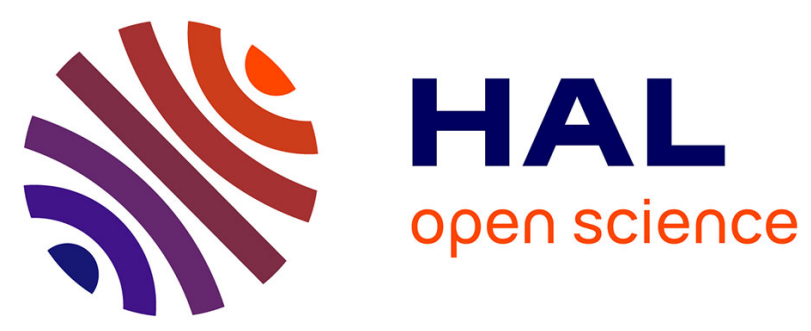

\title{
Unexpected cross-reactivity of anti-cathepsin B antibodies leads to uncertainties regarding the mechanism of action of anti-CD20 monoclonal antibody GA101
}

Wei Wen Chien, Charlène Niogret, Romain Jugé, Loïc Lionnard, Aurélie Cornut-Thibaut, Jérôme Kucharczak, Ariel Savina, Gilles Salles, Abdel Aouacheria

\section{- To cite this version:}

Wei Wen Chien, Charlène Niogret, Romain Jugé, Loïc Lionnard, Aurélie Cornut-Thibaut, et al.. Unexpected cross-reactivity of anti-cathepsin B antibodies leads to uncertainties regarding the mechanism of action of anti-CD20 monoclonal antibody GA101. Leukemia Research, 2017, 55 (2), pp.41-48. 10.1016/j.leukres.2017.01.010 . hal-02355692

\author{
HAL Id: hal-02355692 \\ https://hal.science/hal-02355692
}

Submitted on 8 Nov 2019

HAL is a multi-disciplinary open access archive for the deposit and dissemination of scientific research documents, whether they are published or not. The documents may come from teaching and research institutions in France or abroad, or from public or private research centers.
L'archive ouverte pluridisciplinaire HAL, est destinée au dépôt et à la diffusion de documents scientifiques de niveau recherche, publiés ou non, émanant des établissements d'enseignement et de recherche français ou étrangers, des laboratoires publics ou privés. 


\section{B-cells}

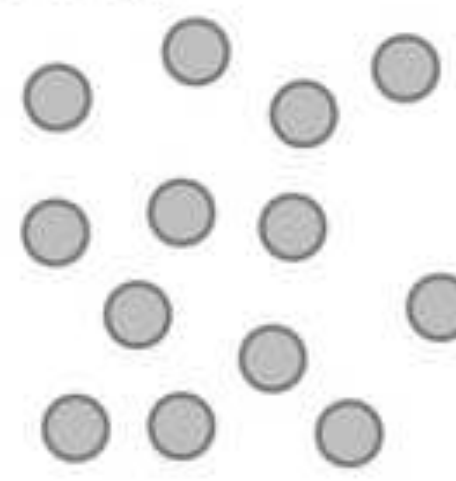

GA101

anticathepsin B MAbs

Non-specific binding to GA101
Homotypic aggregation

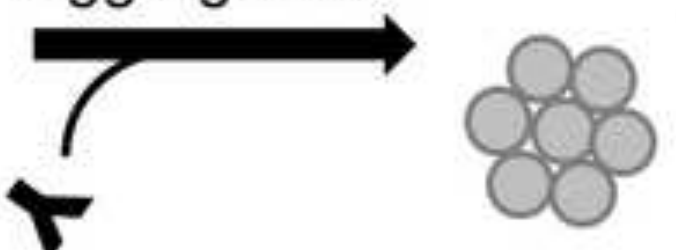

Actin remodeling

ROS production

Cdc42 and NOX activities
Cell death

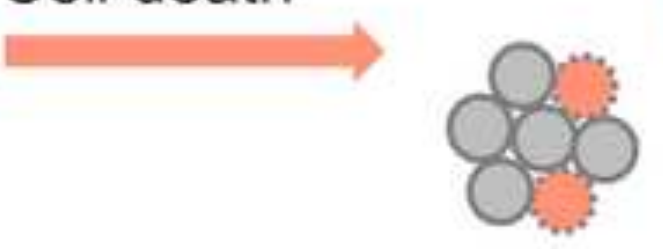

\begin{tabular}{r|r} 
Caspase & \\
MMP & -independent \\
LMP &
\end{tabular} 


\section{Highlights}

Lysosomal and mitochondrial permeabilization events do not occur in response to GA101

Several commercially available anti-cathepsin B antibodies recognize GA101

Cell killing by GA101 (obinutuzumab, Gazyva) may be cathepsin-independent

Cdc42 and NOX-dependent ROS production are possibly involved in GA101 cytotoxicity 


\section{Unexpected cross-reactivity of anti-cathepsin B antibodies leads to uncertainties regarding the mechanism of action of anti-CD20 monoclonal antibody GA101}

Wei Wen Chien ${ }^{a}$, Charlène Niogret ${ }^{\mathrm{a}}$, Romain Jugé ${ }^{\mathrm{a}}$, Loïc Lionnard ${ }^{\mathrm{a}}$, Aurélie Cornut-Thibaut ${ }^{\mathrm{a}}$, Jérôme Kucharczak ${ }^{a}$, Ariel Savina ${ }^{{ }{ }_{*}}$, Gilles Salles ${ }^{a, c_{*}}$ and Abdel Aouacheria ${ }^{a, d *}$

${ }^{\text {a }}$ Molecular Biology of the Cell Laboratory, Ecole Normale Supérieure de Lyon, UMR 5239 CNRS UCBL - ENS Lyon, 46 Allée d'Italie, 69364 Lyon Cedex 07, France

${ }^{\mathrm{b}}$ Institut ROCHE, 30, cours de 1'Ile Seguin, 92650 Boulogne-Billancourt cedex, France

${ }^{\mathrm{c}}$ Hospices Civils de Lyon, Service d'Hématologie, 165 Chemin du Grand Revoyet, 69495, PierreBénite, France

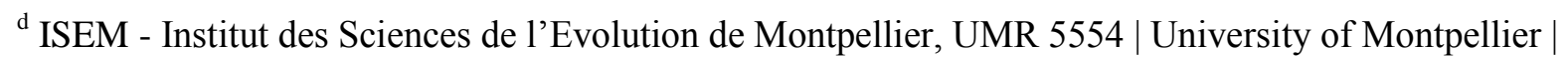
CNRS | IRD | CIRAD | EPHE, Place Eugène Bataillon, 34095 Montpellier, France

* Corresponding author at: ISEM - Institut des Sciences de l'Evolution de Montpellier, UMR 5554 | University of Montpellier |CNRS | IRD | CIRAD | EPHE, Place Eugène Bataillon, 34095 Montpellier, France

E-mail address: abdel.aouacheria@umontpellier.fr (A. Aouacheria). 


\begin{abstract}
GA101, also known as obinutuzumab or Gazyva (Gazyvaro), is a glycoengineered type II humanized antibody that targets the CD20 antigen expressed at the surface of B-cells. This novel anti-CD20 antibody is currently assessed in clinical trials with promising results as a single agent or as part of therapeutic combinations for the treatment of B-cell malignancies. Detailed understanding of the mechanisms of GA101-induced cell death is needed to get insight into possible resistance mechanisms occurring in patients. Although multiple in vitro and in vivo mechanisms have been suggested to describe the effects of GA101 on B-cells, currently available data are ambiguous. The aim of our study was to clarify the cellular mechanisms involved in GA101-induced cell death in vitro, and more particularly the respective roles played by lysosomal and mitochondrial membrane permeabilization. Our results confirm previous reports suggesting that GA101 triggers homotypic adhesion and caspase-independent cell death, two processes that are dependent on actin remodeling and involve the production of reactive oxygen species. With respect to lysosomal membrane permeabilization (LMP), our data suggest that lack of specificity of available antibodies directed against cathepsin B may have confounded previously published results, possibly challenging current LMP-driven model of GA101 action mode.
\end{abstract}

\title{
Key words:
}

Antibody-based immunotherapy, GA101, CD20, cathepsin B, lysosomal permeabilization, lymphomas, cell death 


\section{Introduction}

The CD20 protein, which is selectively expressed on precursor and mature B cells, has been validated as a target antigen for immunotherapy in B-cell malignancies. Rituximab, a Type I chimeric (human/mouse) IgG1 anti-CD20 antibody, was approved for the treatment of patients with B-cell non-Hodgkin lymphoma (NHL) as far back as the late nineties. It has been shown that rituximab binding to CD20 may cause cell death through three distinct mechanisms: (1) activation of complement-dependent cytotoxicity (CDC) after CD20 relocalization into lipid rafts; (2) initiation of antibody-dependent cellular cytotoxicity (ADCC) and phagocytosis (ADCP) via Fc region binding to $\mathrm{Fc} \gamma$ receptors $(\mathrm{Fc} \gamma \mathrm{R})$ on innate immune effectors such as natural killer cells and macrophages; (3) direct induction of programmed cell death (PCD) [1-5]. Addition of rituximab to standard chemotherapy improves the clinical outcome of patients with NHL and chronic lymphocytic leukemia (CLL). However, a significant percentage (30-50\%) of rituximab-treated patients fail to achieve complete or partial remission, and many experience disease relapse [3, 4, 6-14]. This has prompted research efforts to develop novel anti-CD20 antibodies with improved functional properties and greater clinical efficacy [5].

Obinutuzumab (GA101) is a Type II humanized mouse IgG1 $\kappa$ anti-CD20 antibody with a glycoengineered Fc fragment [15] to enhance Fc receptor binding affinity (in particular for FcyRIIIa). GA101 is currently under phase III clinical trials for the treatment of patients with NHL $[16,17]$ and has been approved for patients with previously untreated CLL [18-21]. In vivo studies have indicated superior anti-lymphoma activity for this third-generation antiCD20 antibody over rituximab [15, 22, 23]. Positional mapping showed that the epitope of GA101 partially overlaps the epitope of rituximab and extends towards the C-terminus of CD20 which contributes to the high binding affinity of GA101 for CD20 [5, 15, 24]. Protein 
tomography analysis indicated that, contrary to rituximab bivalent binding to CD20, GA101 preferentially binds to CD20 monovalently, which favors intra- rather than inter-CD20 tetramer binding $[5,24,25]$. Both structural features and CD20-binding characteristics of GA101 make it different from rituximab in terms of mode of action: GA101 does not provoke CD20 relocalization in lipid rafts and subsequent $\mathrm{CDC}$, but induces stronger homotypic adhesion (HA) and direct PCD [5, 15]. In addition, the glycoengineered fragment of GA101 leads to enhanced ADCC and ADCP activity [1, 2, 15, 26, 27].

Although rituximab has been demonstrated to induce apoptosis of non-Hodgkin lymphoma cell lines in vitro [28, 29], evidence from numerous investigations does not appear to support this observation especially in the in vivo context [30-37]. For its part, GA101 is thought to trigger non-apoptotic (necrotic-like) cell death without the need of CD20 cross-linking. The current proposal on the sequence of events leading to GA101-induced "programmed necrosis" is as follows: (i) binding of GA101 to the extracellular domain of CD20 followed by HA, (ii) peripheral reorganization of the actin cytoskeleton, (iii) lysosomal membrane permeabilization (LMP), (iv) cathepsin B release to the cytosol, (v) NADPH oxidase (NOX)mediated (i.e., non-mitochondrial) reactive oxygen species (ROS) production, and (iv) loss of plasma membrane integrity [38, 39].

However, not all cells die by caspase-independent cell death upon exposure to GA101 as both procaspase-3 overexpression and caspase-3 activation were reported in the human nonHodgkin's lymphoma B cell line RL cells [40]. Moreover, cell surface exposure of phosphatidylserine (PS) was consistently observed upon GA101 treatment in a variety of cell lines, raising the possibility of a transition from apoptosis to secondary necrosis for a fraction of the B-cell population $[15,40]$. In fact, there is evidence that GA101 can induce mitochondrial membrane permeabilization (MMP) [39, 41], but this event was considered as secondary to LMP and cathepsin B release [39]. The ability of GA101 to trigger necrosis, 
apoptosis or both may reflect features of the same cell death pathway that converge on mitochondria and/or lysosomes in a cell type- and/or context-specific manner. Alternatively, the choice of GA101-induced cell death by necrosis or apoptosis may depend on which of the two events occurs first: LMP or MMP.

Motivated by these concerns, we sought to undertake an accurate kinetic analysis of LMP and MMP in GA101-treated B cells. The present study was also carried out with the premise that detailed understanding of the role of mitochondria and lysosomes in GA101-induced cell death can provide insights for GA101 use in therapy and help overcome possible resistance mechanisms. 


\section{Material and Methods}

\subsection{Cell culture and treatments}

Raji or SUDHL-4 cells were cultured in RPMI 1640 medium (PAA) containing $10 \%$ fetal calf serum, $2 \mathrm{mM}$ L-glutamine, 100 units penicillin, and 100 $\mu \mathrm{g}$ streptomycin. Cells were seeded at $0.5 \times 10^{6}$ cells $/ \mathrm{mL}$ and treated with $10 \mu \mathrm{g} / \mathrm{ml}$ of GA101 (provided by Roche Pharma) or rituximab (MabThera Lot: H0623, Roche) for different periods of time.

\subsection{HA assay}

Cells were seeded in 8-well imaging chambers (Zell-Kontakt, Germany) and recorded every $5 \mathrm{~min}$ for $24 \mathrm{~h}$ using phase-contrast time-lapse videomicroscopy (inverted Axiovert 100M, Zeiss) in an environment at $37^{\circ} \mathrm{C}$ with $5 \% \mathrm{CO} 2$. In other experiments, microphotographs of untreated cells and cells receiving pre-treatment with different inhibitors or treatment by GA101 were taken using an inverted Leica microscope. Images were processed using ImageJ software.

\subsection{Cell death analysis by flow cytometry}

In a first set of experiments, cells were treated with GA101 or Rituximab for 6, 12, 24 and $48 \mathrm{~h}$ or left untreated. Treated cells were harvested by centrifugation at $1800 \mathrm{rpm}$ for $5 \mathrm{~min}$ and resuspended in $100 \mu \mathrm{L}$ of Annexin V/propidium iodide labeling solution (Annexin-V-FLUOS Staining kit, Roche). Cells were then analyzed by flow cytometry (Becton Dickinson, LSR II) after an incubation period of $15 \mathrm{~min}$ in the dark at room temperature.

In a second set of experiments, cells were first pre-treated with different inhibitors for 1 or $2 \mathrm{~h}$ : Latrunculin B (Enzo Life Science), Tiron (Sigma-Aldrich), Z-VAD-FMK, Z-DEVD-FMK, ZIETD-FMK, Z-LEHD-FMK (BD biosciences), CA-074-Me (Calbiochem), GW4869 (Calbiochem), Nec-1s (Calbiochem), diphenyleneiodonium (Calbiochem), ML141 (Santa 
Cruz). The cells were then left untreated or were treated with GA101 for 6h and analyzed by flow cytometry after AV/PI labeling.

\subsection{ROS detection}

$10^{6}$ cells were first pre-treated for $2 \mathrm{~h}$ with different inhibitors: Latrunculin B, Tiron, DPI, or ML141, and then treated with GA101 and the ROS marker carboxy-H2DCFDA (25mM, Molecular Probes) for 30min, 1h, 3h, 6h or left untreated. Carboxy-H2DCFDA is oxidized in the presence of ROS to carboxy-DCF, which emits green fluorescence. ROS detection was analyzed by flow cytometry and data were processed using the FlowJo software.

\subsection{Subcellular fractionation}

Cells $\left(4 \times 10^{7}\right)$ were harvested $4 \mathrm{~h}$ after treatment with GA101 and rinsed in cold SET buffer (250mM sucrose, $1 \mathrm{mM}$ EDTA, $10 \mathrm{mM}$ Tris, $\mathrm{pH}$ 7.4) by centrifugation at $1200 \mathrm{rpm}$ for $5 \mathrm{~min}$. Cells were resuspended in $0.5 \mathrm{~mL}$ of cold SET buffer containing ETDA-free anti-protease cocktail (APC, Roche) and then subjected to 30 strokes on ice using a Dounce homogenizer. A centrifugation at $1000 \mathrm{~g}$ at $4^{\circ} \mathrm{C}$ for $10 \mathrm{~min}$ was performed to separate supernatant from cell/nuclei pellet. The supernatant was collected and the pellet was resuspended in $0.5 \mathrm{~mL}$ of cold SET buffer containing APC. The suspension was then subjected to another 30 strokes and to centrifugation as described above. The supernatants were pooled and centrifuged at $20000 \mathrm{~g}, 4^{\circ} \mathrm{C}$ for $20 \mathrm{~min}$. The pellet was washed with $1 \mathrm{~mL}$ SET buffer containing APC and lysed with $50 \mu \mathrm{L}$ of lysis buffer (Thermo Scientific) to obtain a mitochondria/lysosome fraction. The supernatant was ultracentrifuged at $100000 \mathrm{~g}$ at $4{ }^{\circ} \mathrm{C}$ for $60 \mathrm{~min}$. The supernatant (corresponding to the cytosol fraction) was collected and the pellet was resuspended in $50 \mu \mathrm{L}$ of lysis buffer to obtain a vesicle-rich fraction. To obtain only the mitochondria/lysosome and cytosolic fractions, treated cells were subjected to the same protocol with SE buffer $(250 \mathrm{mM}$ 
sucrose, 1mM EDTA, pH 7.4) instead of SET solution, skipping out the ultracentrifugation step.

\subsection{Antibodies}

Primary antibodies used were mouse anti-LAMP1 (Abcam), anti-bovine serum albumin (ab79872, Abcam), anti-PDK1 (ab110025, Abcam), anti-cytochrome C (MAB897, BD Pharmingen), anti- $\beta$-actin (A-5441, Sigma), anti- $\alpha$-tubulin (sc-32293, Santa Cruz), and rabbit anti-cathepsin B (EML-SA361, Enzo), anti-cathepsin B (ab30443, Abcam), anti-cathepsin B (sc-13985, Santa Cruz), anti-cathepsin D (ab75852, Abcam), anti-AIF (551429, BD Pharmingen), anti-endonuclease G (3035, ProSci), anti-activated caspase-3 (9661, Cell Signaling), anti-caspase-3 (9662, Cell Signaling). Peroxidase-conjugated secondary antibodies were as follows: rabbit anti-mouse (P0161, Dako), and goat anti-rabbit (12-348, Millipore Corporation) antibodies.

Supplementary Materials and Methods are available. 


\section{Results}

\subsection{GA101 treatment induces rapid and sustained homotypic adhesion}

To test the effect of GA101 on cell-cell adhesion, we selected Raji cells, a prototypical chemoresistant BL-derived cell line expressing high level of CD20 (data not shown). As shown in Fig. 1, under normal culture conditions, Raji cells displayed a natural tendency to form clusters. Within $1 \mathrm{~h}$ of treatment by GA101, adjacent cells underwent marked HA, forming large cellular aggregates. Rituximab also induced HA of Raji cells, with virtually similar kinetics. We also observed that the addition of GA101 or rituximab to SUDHL-4 cells, a human diffuse large B-cell lymphoma cell line, also triggered HA, albeit with distinct kinetics (GA101: 1h; rituximab: 4h) (Supplementary Fig. 1). Thus, although HA seems to be of larger amplitude and higher velocity with GA101, induction of this phenomenon is not restricted to this mAb and appears to be a shared property with rituximab.

\subsection{GA101-treated cells undergo cell death through a caspase-independent pathway}

Apoptosis and necrosis are two types of cell death with distinct morphological and biochemical features. Apoptotic cells are often characterized by fragmented nuclei, PS surface exposure, separation of cell fragments into apoptotic bodies, whereas necrotic cells are mainly defined by loss of plasma membrane integrity and swelling of cellular organelles including mitochondria [42]. Although programmed necrosis has been suggested to represent the major route to cell death in GA101-treated cells [38, 39], GA101 has also been reported to trigger cell death showing a mixture of hallmarks typically found in apoptosis and necrosis $[15,40]$. To gain further insight into this issue, we performed dual staining with fluorescent Annexin V (AV) and propidium iodide (PI) (on mechanically dissociated cells) followed by flow cytometry to distinguish between apoptotic and necrotic cell populations following treatment by GA101. In this test, AV+ (positive)/PI- (negative) cells are classically considered as 
apoptotic cells and PI+cells as necrotic cells. However, it is the movement of cells from AV/PI- status (viable) to AV+/PI- (early apoptotic cells with membrane integrity) and eventually to $\mathrm{AV}+/ \mathrm{PI}+$ (end stage apoptosis or secondary necrosis, with plasma membrane rupture) which is truly indicative of apoptosis (AV-/PI+ cells corresponding to primary necrotic cells). As shown in Fig. 2A, GA101 treatment reduced the viable cell fraction by $60 \% 6 \mathrm{~h}$ posttreatment. Approximately $20 \%$ of GA101-treated cells showed AV+/PI- staining at $6 \mathrm{~h}$, and the proportion of $\mathrm{AV}+/ \mathrm{PI}-$ cells gradually diminished to less than $2 \%$ at $48 \mathrm{~h}$ post-treatment. The proportion of AV+/PI+ cells followed a similar pattern, whereas the percentage of AV$/ \mathrm{PI}+$ cells, which was about $4 \%$ at $6 \mathrm{~h}$, roughly doubled during the assessed time points to reach $30 \%$ at 48 h. Rituximab was less efficient than GA101 in inducing the death of Raji cells and AV+/PI+ dead cells were only marginally detected after treatment with this antibody (Fig. 2A). Our results indicate that GA101 addition did not result in the classical phenotypic pattern of cells transitioning from early apoptosis to late apoptosis and necrosis.

Pre-treatment with a pan-caspase chemical inhibitor or with caspase selective inhibitors had almost no effect on the proportion of cells stained with AV and/or PI (Fig. 2B), further suggesting that this cell death is not induced through a caspase-dependent apoptotic pathway. These observations suggest that either (i) GA101 promotes caspase-independent apoptosis in a subpopulation of Raji cells and necrosis in another subpopulation of the cell culture, (ii) or that the process by which cells undergo their demise exhibit both apoptotic-like and necroticlike signatures. Note that induction of cell death by GA101 also appears to be independent of RIPK1 (a necrosis mediator) or sphingomyelinase (an apoptotic mediator) activity (Supplementary Fig. 2).

\subsection{Inhibition of actin remodeling and oxidative damage but not of cathepsin $B$ activity can protect cells against GA101-induced cell death}


Reorganization of cortical actin cytoskeleton and production of ROS by NOX following cytosolic release of active cathepsin B from lysosomes have been suggested to play a key role in GA101-induced cell death of B-lymphoma cells [38, 39]. Here, we examined the effect of inhibiting actin polymerization (with Latrunculin B, Lat B), cathepsin B activity (with CA074-Me, a membrane-permeable selective inhibitor of this enzyme) or ROS function (by using the ROS scavenger Tiron) on the death of Raji cells cultured in presence of GA101. As shown in Fig. 2C, the death of GA101-treated cells was fully prevented when the cells were pre-treated with LatB, confirming the upstream role of actin remodeling in the death cascade. Pre-treatment with Tiron partially reduced cell mortality after GA101 treatment, mainly by decreasing the percentage of $\mathrm{AV}+\mathrm{PI}+(27 \%)$ and $\mathrm{AV}-/ \mathrm{PI}+$ cells $(11 \%)$. In contrast, pretreatment with CA-074-Me could not rescue Raji cells from GA101-induced death (Fig. 2C).

These results demonstrate that actin reorganization and ROS production are involved in the induction of cell death by GA101, but challenge a role for cathepsin B in this process. We thus decided to undertake biochemical experiments to formally determine whether or not LMP and/or MMP occur in response to GA101 addition.

\subsection{MMP and LMP do not occur in response to GA101}

To determine whether MMP takes place during GA101-induced cell death, we analyzed the localization of a panel of mitochondrial proteins following GA101 treatment: PDK1, a mitochondrial matrix protein, and Cytochrome c (Cyt-c), Endonuclease G (EndoG) and AIF, three mitochondrial intermembrane proteins respectively involved in apoptosis (Cyt-c) or caspase-independent cell death (EndoG, AIF). Untreated cells and GA101-treated cells were subjected to subcellular fractionation to obtain a fraction enriched in mitochondria and lysosomes (Mito/Lyso) and a cytosolic fraction. As shown in Fig. 3A, at each time point, the abundance of PDK1, Cyt-c, EndoG and AIF in the Mito/Lyso fraction of GA101-treated cells 
was nearly identical to that found in the Mito/Lyso fraction of untreated cells. Importantly, no significant release of these proteins into the cytosol or change in their amount in the Mito/Lyso fraction was detected with GA101-treated cells (except for EndoG, which was slightly more abundant in the Mito/Lyso fraction following GA101 treatment). Similarly, there was no observable increase in the quantity of active caspase- 3 in the cytosolic fraction of GA101-treated cells, compared to controls (Fig. 3A). UVB-induced cleavage of caspase-3 and cytosolic release of Cyt-c were used as positive controls for MMP (Supplementary Fig. 3). Collectively, these data indicate that GA101 treatment did not trigger MMP and processing of the effector caspase-3.

In parallel, we analyzed if LMP, assessed by the release of active cathepsin B from lysosomes into the cytosol, occurred following GA101 treatment. Because cathepsin B can be detected in non-lysosomal compartments such as secretory granules [43-45], subcellular fractionation was conducted using lysates from untreated cells or GA101-treated cells to generate a cytosolic fraction, a Mito/Lyso fraction and a fraction containing vesicles (including Golgi- or microtubule-associated vesicles, endosomal and secretory vesicles). Cathepsin B usually exists as three forms: two pro-enzyme forms (38 kDa and $44 \mathrm{kDa}$, respectively) and an active form $(31 \mathrm{kDa})[46,47]$. As shown in Fig. 3B, in untreated cells, active cathepsin B was detected in the Mito/Lyso and vesicle fractions but not in the cytosolic fraction. However, contrary to expectations, active cathepsin B was not found in the cytosolic fraction following GA101 treatment. This observation was extended to another lysosomal protein, cathepsin D, which like cathepsin B was not released from lysosomes to the cytosol upon exposure to GA101 (Fig. 3B) (note that cytosolic release of cathepsin D was observed after $\mathrm{H}_{2} \mathrm{O}_{2}$ treatment, see Supplementary Fig. 4). In addition, in contrast to a previous report [38], active cathepsin B was not released into the extracellular medium after GA101 treatment. Like 
cathepsin B, the active form of cathepsin D was also undetectable in the extracellular medium derived from GA101-treated samples (Fig. 4A, upper panel, lanes 1-6).

Taken together, these results demonstrate that based on biochemical experiments, MMP and LMP do not occur in cells in response to GA101 treatment.

\subsection{Polyclonal antibody ab30443 non-specifically binds to GA101}

Our findings showing that GA101 does not trigger neither MMP nor LMP were in conflict with previously published data [38]. One possible explanation for this discrepancy was the use of different antibodies against cathepsin B. The authors of the above-cited publication used a rabbit serum polyclonal anti-cathepsin B antibody (ab30443) purchased from the Abcam company (Dr. Honeychurch, personal communication), while we used a commercial rabbit polyclonal antibody from Santa Cruz (sc-13985). As shown in Fig. 5A, antibody ab30443 revealed a clear signal at around $30 \mathrm{kDa}$ when tested by western blot on the Mito/Lyso fractions derived from GA101-treated cells. This antibody also gave a positive signal with the extracellular medium (Fig. 5B) but not the cytosolic fraction of cells treated with GA101 (Fig. 5A), a result seemingly consistent with previously published observations [38]. However, quite surprisingly, a signal of identical molecular mass was also detected in samples of pure culture medium conditioned with GA101 in the complete absence of cells (Fig. 4A, lower panel, lanes 7-9). Furthermore, when we treated CD20-negative Jurkat cells with GA101 (i.e., human T lymphocytes which are not expected to react to GA101), we still observed a strong signal in the extracellular medium sample when probing the membrane with antibody ab30443 but not with antibody sc-13985 (Fig. 4B). A reasonable explanation for this unexpected finding is that ab30443 antibodies actually recognize GA101 chains (presumably the light chain which has an estimated MW of $24 \mathrm{kDa}$, CHEMBL1743048) instead of (or in addition to) cathepsin $\mathrm{B}$. 
In support to this hypothesis, we showed by immunofluorescence that ab30443 stained the surface and the pericortical region of GA101-treated Raji cells, and that this staining did not colocalize with the lysosomal compartment (Supplementary Fig. 5, upper panels). In contrast, by using the antibody sc-13985 specific to cathepsin B, we obtained a cytoplasmic labeling of cathepsin B in both non-treated and GA101-treated cells. In both cell populations, this antibody yielded a staining pattern consistent with partial colocalization with the lysosomal marker LAMP-1 (Supplementary Fig. 5, bottom panels).

During the course of this study, we also found that, in addition to ab30443, another commercially available rabbit serum polyclonal anti-cathepsin B antibody, EML-SA361, has an irrelevant specificity towards GA101 antibody chains (Supplementary Table 1, Fig. 4A, lower panel, lanes 7-9 and Supplementary Fig. 6). Altogether, our data point to major issues in the specificity of several commercial antibodies directed against cathepsin B when they are used in experiments in which GA101 or other related antibodies are present.

\subsection{The activation status of major signaling and apoptotic molecules is only minimally modified by GA101 exposure}

Since GA101-induced cell death did not seem to require MMP or LMP, we were interested in dissecting upstream signaling events that link GA101-CD20 ligation and commitment to cell death. We used a protein array strategy to examine the activation status of key signaling molecules at baseline or after treatment with GA101. Changes in the phosphorylation of various well-known actors of survival- and apoptosis-regulatory pathways were analyzed at different time after antibody addition. The phosphorylation levels of most of the analyzed proteins did not vary in response to GA101, compared to untreated samples (Supplementary Fig. 7). 


\subsection{Possible involvement of the Rho GTPase Cdc42 and NOX-dependent ROS production in GA101-induced cytotoxicity}

We next devoted efforts to investigate the link between the early response (actin remodeling and HA) of B-lymphoma cells to GA101 and subsequent cell death events (i.e. increased oxidative stress). It has been reported that Cdc42, a member of the Rho family of GTPases, regulates actin reorganization and NOX-mediated ROS production [48], and can be activated in response to several cytotoxic chemicals (e.g. arsenic, ethanol and mycophenolic acid) [4951]. Therefore, we investigated a potential role of Cdc42 in GA101-induced HA and cell death. Pre-treatment with the Cdc42 GTPase inhibitor ML141 or with the NOX inhibitor DPI prevented HA of Raji cells treated by GA101 (Supplementary Fig. 8A) and partially rescued these cells from GA101-induced cell death (Supplementary Fig. 8B). Pre-incubation with Lat B or DPI significantly reduced ROS production at $3 \mathrm{~h}$ and $6 \mathrm{~h}$ post-treatment, compared to cells pre-incubated with DMSO. In contrast, pre-treatment with ML141 could not prevent ROS production and even exacerbated it (Supplementary Fig. 8C). These results based on the use of chemical inhibitors suggest that in response to GA101 (i) the activities of Cdc42 and NOX may be involved in the induction of cell death; (ii) both actin remodeling and NOX activity may be implicated in HA and ROS production; (iii) Cdc42 activity may control HA but not ROS production. 


\section{Discussion}

Previous studies on human cellular models have produced ambiguous results about the modality by which B-cells die in vitro upon GA101 treatment [15, 38-41], leaving the process of GA101-induced cell killing unclear. The aim of our study was to clarify the mode of cell death induced by GA101 in vitro, and in particular the potential involvement of lysosomal (LMP) and mitochondrial permeabilization (MMP) events. We provided definitive evidence that GA101 triggers HA and death of B-cells in culture, two processes absolutely dependent on actin remodeling and involving ROS production, as previously published [38, 39]. Our results showed that GA101 triggers a form of caspase-independent cell death exhibiting both apoptotic and necrotic features, also consistent with previous reports $[38,40]$.

Unexpectedly, by using biochemical techniques, we failed to detect clear evidence of MMP and LMP in GA101-treated cells, contrary to the literature [38, 39, 41]. In previous reports, LMP was inferred partly based on increased Lysotracker red or acridin orange stainings [38, 39]. However, general decrease in intracellular $\mathrm{pH}$ (as detected by lysotracker or acridine orange and incorrectly defined as LMP) might or might not be accompanied by LMP. The second argument in support of LMP relates to the fact that cathepsin B was seemingly detected in the extracellular medium of GA101-treated cells, contrary to Rituximab-treated cells or control cells (see Figure 6C in [38]; but note that signal saturation is obvious for BSA in the GA101 lane compared to Rituximab, resulting in a wrong quantitation of Cathepsin B signals). Increased cathepsin D expression was also previously reported in GA101-treated multicellular aggregates of lymphoma cells [41], but experiments were made using total cell lysates (prior to western blot analysis) (Dr. Bezombes, personal communication) and therefore do not provide any information as to whether cathepsin $\mathrm{D}$ was genuinely released from lysosomes. In our hands, lysosomal release of cathepsins B and D, assessed using specific 
antibodies after cell fractionation, was not observed in GA101-treated Raji or SUDHL-4 cells. We therefore argue that lack of specificity of the commercial ab30443 antibody against cathepsin B probably resulted in misleading interpretations of cathepsin B release from lysosomes or secretion into the extracellular medium in response to GA101 treatment. This unexpected finding challenges current assumptions about the action mode of GA101 [38, 39, 41].

\section{Conclusions}

Although GA101 represents a promising new option for patients with B-cell malignancies, its mechanism of action remains enigmatic, at least in vitro. GA101-CD20 ligation is followed by an asynchronous process of cell mortality that do not strictly conform the criteria of apoptosis or programmed necrosis, two genetically-determined programs of cell death. The fact that HA represents a linchpin in GA101 action mode suggests that direct plasmamembrane-associated events (e.g. Cdc42 and NOX activities), physical stress due to HA or aggregation-induced aberrant genetic expression might play a role in the death sentence.

\section{Author contributions}

WWC organized the investigation, performed the experiments, analyzed data, interpreted results, prepared all figures/tables, and wrote the manuscript text. $\mathrm{CN}$ performed the experiments and analyzed data. LL and ACT performed the experiments. RJ performed protein array quantification. JK, AS and GS assisted to the research design and contributed to critical analysis of the results. AA directed, oversaw the research design, assisted in the experiment design, interpreted results and wrote the manuscript text. All co-authors critically reviewed the manuscript and all approved its final version. 


\section{Disclosures/conflict of interest}

AS is employee of Institut Roche. The remaining authors declare no competing financial interests.

\section{Acknowledgments}

This work was supported by grants from Roche Pharma, La Ligue Contre le Cancer (Comité

de la Loire) and Institut Carnot CALYM. RJ is a recipient of a CIFRE doctoral fellowship from ANRT. We thank Christian Klein, Roche Innovation Center Zurich for support and critical reading of the manuscript.

\section{References}

[1] Glennie MJ, French RR, Cragg MS, Taylor RP. Mechanisms of killing by anti-CD20 monoclonal antibodies. Molecular immunology. 2007;44:3823-37.

[2] Lim SH, Beers SA, French RR, Johnson PW, Glennie MJ, Cragg MS. Anti-CD20 monoclonal antibodies: historical and future perspectives. Haematologica. 2010;95:135-43.

[3] van Meerten T, Hagenbeek A. CD20-targeted therapy: the next generation of antibodies. Seminars in hematology. 2010;47:199-210.

[4] Rezvani AR, Maloney DG. Rituximab resistance. Best practice \& research Clinical haematology. 2011;24:203-16.

[5] Klein C, Lammens A, Schafer W, Georges G, Schwaiger M, Mossner E, et al. Epitope interactions of monoclonal antibodies targeting CD20 and their relationship to functional properties. mAbs.

2013;5:22-33.

[6] Forstpointner R, Dreyling M, Repp R, Hermann S, Hanel A, Metzner B, et al. The addition of rituximab to a combination of fludarabine, cyclophosphamide, mitoxantrone (FCM) significantly increases the response rate and prolongs survival as compared with FCM alone in patients with relapsed and refractory follicular and mantle cell lymphomas: results of a prospective randomized study of the German Low-Grade Lymphoma Study Group. Blood. 2004;104:3064-71.

[7] Marcus R, Imrie K, Belch A, Cunningham D, Flores E, Catalano J, et al. CVP chemotherapy plus rituximab compared with CVP as first-line treatment for advanced follicular lymphoma. Blood. 2005;105:1417-23.

[8] Hiddemann W, Kneba M, Dreyling M, Schmitz N, Lengfelder E, Schmits R, et al. Frontline therapy with rituximab added to the combination of cyclophosphamide, doxorubicin, vincristine, and prednisone (CHOP) significantly improves the outcome for patients with advanced-stage follicular lymphoma compared with therapy with CHOP alone: results of a prospective randomized study of the German Low-Grade Lymphoma Study Group. Blood. 2005;106:3725-32.

[9] Habermann TM, Weller EA, Morrison VA, Gascoyne RD, Cassileth PA, Cohn JB, et al. RituximabCHOP versus $\mathrm{CHOP}$ alone or with maintenance rituximab in older patients with diffuse large $\mathrm{B}$-cell lymphoma. Journal of clinical oncology : official journal of the American Society of Clinical Oncology. 2006;24:3121-7. 
[10] Pfreundschuh M, Trumper L, Osterborg A, Pettengell R, Trneny M, Imrie K, et al. CHOP-like chemotherapy plus rituximab versus $\mathrm{CHOP}$-like chemotherapy alone in young patients with goodprognosis diffuse large-B-cell lymphoma: a randomised controlled trial by the MabThera International Trial (MInT) Group. The Lancet Oncology. 2006;7:379-91.

[11] Herold M, Haas A, Srock S, Neser S, Al-Ali KH, Neubauer A, et al. Rituximab added to first-line mitoxantrone, chlorambucil, and prednisolone chemotherapy followed by interferon maintenance prolongs survival in patients with advanced follicular lymphoma: an East German Study Group Hematology and Oncology Study. Journal of clinical oncology : official journal of the American Society of Clinical Oncology. 2007;25:1986-92.

[12] Salles G, Mounier N, de Guibert S, Morschhauser F, Doyen C, Rossi JF, et al. Rituximab combined with chemotherapy and interferon in follicular lymphoma patients: results of the GELA-GOELAMS FL2000 study. Blood. 2008;112:4824-31.

[13] Hallek M, Fischer K, Fingerle-Rowson G, Fink AM, Busch R, Mayer J, et al. Addition of rituximab to fludarabine and cyclophosphamide in patients with chronic lymphocytic leukaemia: a randomised, open-label, phase 3 trial. Lancet. 2010;376:1164-74.

[14] Keating GM. Rituximab: a review of its use in chronic lymphocytic leukaemia, low-grade or follicular lymphoma and diffuse large B-cell lymphoma. Drugs. 2010;70:1445-76.

[15] Mossner E, Brunker P, Moser S, Puntener U, Schmidt C, Herter S, et al. Increasing the efficacy of CD20 antibody therapy through the engineering of a new type II anti-CD20 antibody with enhanced direct and immune effector cell-mediated B-cell cytotoxicity. Blood. 2010;115:4393-402.

[16] Illidge T, Cheadle EJ, Donaghy C, Honeychurch J. Update on obinutuzumab in the treatment of Bcell malignancies. Expert opinion on biological therapy. 2014;14:1507-17.

[17] Goede V, Klein C, Stilgenbauer S. Obinutuzumab (GA101) for the treatment of chronic lymphocytic leukemia and other B-cell non-hodgkin's lymphomas: a glycoengineered type II CD20 antibody. Oncology research and treatment. 2015;38:185-92.

[18] Sachdeva M, Dhingra S. Obinutuzumab: A FDA approved monoclonal antibody in the treatment of untreated chronic lymphocytic leukemia. International journal of applied \& basic medical research. 2015;5:54-7.

[19] Hoy SM. Obinutuzumab: A Review of Its Use in Patients with Chronic Lymphocytic Leukaemia. Drugs. 2015.

[20] Cameron F, McCormack PL. Obinutuzumab: first global approval. Drugs. 2014;74:147-54. [21] Lee HZ, Miller BW, Kwitkowski VE, Ricci S, DelValle P, Saber H, et al. U.S. Food and drug administration approval: obinutuzumab in combination with chlorambucil for the treatment of previously untreated chronic lymphocytic leukemia. Clinical cancer research : an official journal of the American Association for Cancer Research. 2014;20:3902-7.

[22] Herter S, Herting F, Mundigl O, Waldhauer I, Weinzierl T, Fauti T, et al. Preclinical activity of the type II CD20 antibody GA101 (obinutuzumab) compared with rituximab and ofatumumab in vitro and in xenograft models. Molecular cancer therapeutics. 2013;12:2031-42.

[23] Herting F, Friess T, Bader S, Muth G, Holzlwimmer G, Rieder N, et al. Enhanced anti-tumor activity of the glycoengineered type II CD20 antibody obinutuzumab (GA101) in combination with chemotherapy in xenograft models of human lymphoma. Leukemia \& lymphoma. 2014;55:2151-5160. [24] Niederfellner G, Lammens A, Mundigl O, Georges GJ, Schaefer W, Schwaiger M, et al. Epitope characterization and crystal structure of GA101 provide insights into the molecular basis for type I/II distinction of CD20 antibodies. Blood. 2011;118:358-67.

[25] Cragg MS. CD20 antibodies: doing the time warp. Blood. 2011;118:219-20.

[26] Golay J, Da Roit F, Bologna L, Ferrara C, Leusen JH, Rambaldi A, et al. Glycoengineered CD20 antibody obinutuzumab activates neutrophils and mediates phagocytosis through CD16B more efficiently than rituximab. Blood. 2013;122:3482-91.

[27] Herter S, Birk MC, Klein C, Gerdes C, Umana P, Bacac M. Glycoengineering of therapeutic antibodies enhances monocyte/macrophage-mediated phagocytosis and cytotoxicity. J Immunol. 2014;192:2252-60. 
[28] Hofmeister JK, Cooney D, Coggeshall KM. Clustered CD20 induced apoptosis: src-family kinase, the proximal regulator of tyrosine phosphorylation, calcium influx, and caspase 3-dependent apoptosis. Blood cells, molecules \& diseases. 2000;26:133-43.

[29] van der Kolk LE, Evers LM, Omene C, Lens SM, Lederman S, van Lier RA, et al. CD20-induced B cell death can bypass mitochondria and caspase activation. Leukemia. 2002;16:1735-44.

[30] Beurskens FJ, Lindorfer MA, Farooqui M, Beum PV, Engelberts P, Mackus WJ, et al. Exhaustion of cytotoxic effector systems may limit monoclonal antibody-based immunotherapy in cancer patients. J Immunol. 2012;188:3532-41.

[31] Bologna L, Gotti E, Manganini M, Rambaldi A, Intermesoli T, Introna M, et al. Mechanism of action of type II, glycoengineered, anti-CD20 monoclonal antibody GA101 in B-chronic lymphocytic leukemia whole blood assays in comparison with rituximab and alemtuzumab. J Immunol.

2011;186:3762-9.

[32] Boross P, Jansen JH, de Haij S, Beurskens FJ, van der Poel CE, Bevaart L, et al. The in vivo mechanism of action of CD20 monoclonal antibodies depends on local tumor burden. Haematologica. 2011;96:1822-30.

[33] de Haij S, Jansen JH, Boross P, Beurskens FJ, Bakema JE, Bos DL, et al. In vivo cytotoxicity of type I CD20 antibodies critically depends on Fc receptor ITAM signaling. Cancer research. 2010;70:3209-17.

[34] Li B, Shi S, Qian W, Zhao L, Zhang D, Hou S, et al. Development of novel tetravalent anti-CD20 antibodies with potent antitumor activity. Cancer research. 2008;68:2400-8.

[35] Mishima Y, Sugimura N, Matsumoto-Mishima Y, Terui Y, Takeuchi K, Asai S, et al. An imagingbased rapid evaluation method for complement-dependent cytotoxicity discriminated clinical response to rituximab-containing chemotherapy. Clinical cancer research : an official journal of the American Association for Cancer Research. 2009;15:3624-32.

[36] Montalvao F, Garcia Z, Celli S, Breart B, Deguine J, Van Rooijen N, et al. The mechanism of antiCD20-mediated $B$ cell depletion revealed by intravital imaging. The Journal of clinical investigation. 2013;123:5098-103.

[37] Wilson NS, Yang B, Yang A, Loeser S, Marsters S, Lawrence D, et al. An Fcgamma receptordependent mechanism drives antibody-mediated target-receptor signaling in cancer cells. Cancer cell. 2011;19:101-13.

[38] Alduaij W, Ivanov A, Honeychurch J, Cheadle EJ, Potluri S, Lim SH, et al. Novel type II anti-CD20 monoclonal antibody (GA101) evokes homotypic adhesion and actin-dependent, lysosome-mediated cell death in B-cell malignancies. Blood. 2011;117:4519-29.

[39] Honeychurch J, Alduaij W, Azizyan M, Cheadle EJ, Pelicano H, Ivanov A, et al. Antibody-induced nonapoptotic cell death in human lymphoma and leukemia cells is mediated through a novel reactive oxygen species-dependent pathway. Blood. 2012;119:3523-33.

[40] Dalle S, Reslan L, Besseyre de Horts T, Herveau S, Herting F, Plesa A, et al. Preclinical studies on the mechanism of action and the anti-lymphoma activity of the novel anti-CD20 antibody GA101. Molecular cancer therapeutics. 2011;10:178-85.

[41] Decaup E, Jean C, Laurent C, Gravelle P, Fruchon S, Capilla F, et al. Anti-tumor activity of obinutuzumab and rituximab in a follicular lymphoma 3D model. Blood cancer journal. 2013;3:e131. [42] Wyllie AH, Kerr JF, Currie AR. Cell death: the significance of apoptosis. International review of cytology. 1980;68:251-306.

[43] Ulbricht B, Henny H, Horstmann H, Spring H, Faigle W, Spiess E. Influence of 12(S)hydroxyeicosatetraenoic acid (12(S)-HETE) on the localization of cathepsin B and cathepsin L in human lung tumor cells. European journal of cell biology. 1997;74:294-301.

[44] Balaji KN, Schaschke N, Machleidt W, Catalfamo M, Henkart PA. Surface cathepsin B protects cytotoxic lymphocytes from self-destruction after degranulation. The Journal of experimental medicine. 2002;196:493-503.

[45] Hook VY, Kindy M, Hook G. Inhibitors of cathepsin B improve memory and reduce beta-amyloid in transgenic Alzheimer disease mice expressing the wild-type, but not the Swedish mutant, betasecretase site of the amyloid precursor protein. The Journal of biological chemistry. 2008;283:774553. 
[46] Mach L, Stuwe K, Hagen A, Ballaun C, Glossl J. Proteolytic processing and glycosylation of cathepsin B. The role of the primary structure of the latent precursor and of the carbohydrate moiety for cell-type-specific molecular forms of the enzyme. The Biochemical journal. 1992;282 ( Pt 2):57782.

[47] Linebaugh BE, Sameni M, Day NA, Sloane BF, Keppler D. Exocytosis of active cathepsin B enzyme activity at $\mathrm{pH} 7.0$, inhibition and molecular mass. European journal of biochemistry / FEBS. 1999;264:100-9.

[48] Cotteret S, Chernoff J. The evolutionary history of effectors downstream of Cdc42 and Rac. Genome biology. 2002;3:REVIEWSO002.

[49] Qian Y, Liu KJ, Chen Y, Flynn DC, Castranova V, Shi X. Cdc42 regulates arsenic-induced NADPH oxidase activation and cell migration through actin filament reorganization. The Journal of biological chemistry. 2005;280:3875-84.

[50] Wang X, Ke Z, Chen G, Xu M, Bower KA, Frank JA, et al. Cdc42-dependent activation of NADPH oxidase is involved in ethanol-induced neuronal oxidative stress. PloS one. 2012;7:e38075.

[51] Chaigne-Delalande B, Guidicelli G, Couzi L, Merville P, Mahfouf W, Bouchet S, et al. The immunosuppressor mycophenolic acid kills activated lymphocytes by inducing a nonclassical actindependent necrotic signal. J Immunol. 2008;181:7630-8. 


\section{Figure legends}

Figure 1: GA101 or rituximab induce homotypic adhesion of Raji cells.

Microphotographs of control cells and cells treated with GA101 or rituximab $(10 \mu \mathrm{g} / \mathrm{ml})$ were taken at 1, 4, 8, 12 and 20 h post-treatment using phase contrast videomicroscopy (Objective: 10x, scale bar: $100 \mu \mathrm{m})$. Identical experiments were carried out using SUDHL-4 cells leading to similar results (not shown).

Figure 2: Cell death induced by GA101 is independent of both caspase and cathepsin B activities but involves actin polymerization and ROS production. Flow cytometric analysis of Annexin-V (AV) and propidium iodide (PI) staining of Raji cells. (A) Cells were treated with GA101 or rituximab $(10 \mu \mathrm{g} / \mathrm{ml})$ for $6,12,24$ and $48 \mathrm{~h}$. Untreated cells were prepared at each time point as controls. (B) Cells were incubated with $40 \mu \mathrm{M}$ of broadspectrum caspase inhibitor (Z-VAD-FMK), caspase-3 inhibitor (Z-DEVD-FMK), caspase-8 inhibitor (Z-IETD-FMK) or caspase-9 inhibitor (Z-LEHD-FMK) for $1 \mathrm{~h}$ and then treated with $10 \mu \mathrm{g} / \mathrm{ml}$ of GA101 for $6 \mathrm{~h}$. Cells treated with DMSO were prepared as controls. (C) Cells were pre-treated with $20 \mu \mathrm{M}$ of actin polymerization inhibitor (Latrunculin B, LatB), $20 \mathrm{mM}$ ROS scavenger (Tiron) or $200 \mu \mathrm{M}$ cathepsin B inhibitor (CA-074-Me) for $1 \mathrm{~h}$ and then treated with $10 \mu \mathrm{g} / \mathrm{ml}$ of GA101 or $0.5 \mathrm{mM} \mathrm{H}_{2} \mathrm{O}_{2}$ for $6 \mathrm{~h}$. Cells treated with DMSO were prepared as controls.

Figure 3: MMP and LMP do not occur following GA101 treatment. (A) Cells were left untreated or treated with $10 \mu \mathrm{g} / \mathrm{ml}$ of GA101 for 6,12 or $24 \mathrm{~h}$, and subcellular fractionation followed by western blot analysis was performed. Abundance of the assayed mitochondrial 
proteins in the mitochondria/lysosome (Mito/Lyso) fraction and in the cytosolic fraction was analyzed by western blotting. The MW ( $\mathrm{kDa})$ of each protein is indicated. At each time point, the abundance of PDK1, cytochrome C, Endonuclease G, and AIF in the Mito/Lyso fraction of GA101-treated Raji cells was similar to that found in the Mito/Lyso fraction of untreated cells. The presence of these proteins only in the Mito/Lyso fraction but not in the cytosolic fraction shows that subcellular fractionation was successful. No significant increase was observed in the quantity of the assayed proteins or in that of active caspase- 3 in the cytosolic fraction of GA101-treated Raji cells, compared to controls. Note that actin, which was used as control for equal loading, was less abundant in the Mito/Lyso fraction after GA101 addition. (B) Cells were left untreated or treated with $10 \mu \mathrm{g} / \mathrm{ml}$ of GA101 for $6 \mathrm{~h}$, followed by subcellular fractionation. Abundance of lysosomal-associated membrane protein 1 (LAMP1), cathepsin B (labeled using antibody sc-13985) and cathepsin D in the mitochondria/lysosome (Mito/Lyso) fraction, in the cytosolic fraction and in the vesicle-rich fraction was analyzed by western blot. The MW (kDa) of each protein is indicated. NT: non-treated, GA: GA101. Similar results were obtained using SUDHL-4 cells (not shown).

\section{Figure 4: Cathepsins B and D are not released into the extracellular medium of cultured}

B cells after GA101 treatment. Raji cells were left untreated or treated with $10 \mu \mathrm{g} / \mathrm{ml}$ of GA101 or rituximab for $6 \mathrm{~h}$ and cell lysates were prepared. Samples of the extracellular media of cultured cells treated with GA101 or rituximab were prepared as well as samples of pure fresh medium supplemented with GA101 or rituximab. Medium and protein samples were run on acrylamide gels for western blot analysis. (A) Upper panel: membranes were labeled using anti-cathepsin B antibody sc-13985 or anti-cathepsin D antibody. Lower panel: immunoblot using anti-cathepsin antibodies ab30443 or EML-SA361. (B) Jurkat cells were left untreated or were treated with $10 \mu \mathrm{g} / \mathrm{mL}$ of GA101 for $6 \mathrm{~h}$. Cell lysates and extracellular media were collected for western blot analysis. Pure medium alone and medium containing $10 \mu \mathrm{g} / \mathrm{mL}$ of 
GA101 were used as controls. Ab30443 antibody displays non-specific reactivity toward GA101. In contrast, sc-13985 antibody specifically recognizes cathepsin B. NT: non-treated, Rt: rituximab, GA: GA101, BSA: bovine serum albumin, a component of fetal bovine serum used in culture medium preparation. The MW (kDa) of each protein is indicated.

\section{Figure 5: Antibody Ab30443 exhibits non-specific reactivity towards GA101. (A) Raji} cells were left untreated or treated with $10 \mu \mathrm{g} / \mathrm{ml}$ of GA101 for $6,12,24 \mathrm{~h}$, followed by subcellular fractionation and western blot analysis. Abundance of the assayed lysosomal proteins in the mitochondria/lysosome (Mito/Lyso) fraction and in the cytosolic fraction was analyzed by western blot. (B) Samples of extracellular media of untreated or GA101-treated cells were collected for western blot analysis. The signal obtained is identical to (A), indicating that ab30443 recognizes the GA101 antibody and not a cellular protein (such as lysosomal Cathepsin B). *: membranes labeled using antibody ab30443. 


\section{Hours untreated}

0
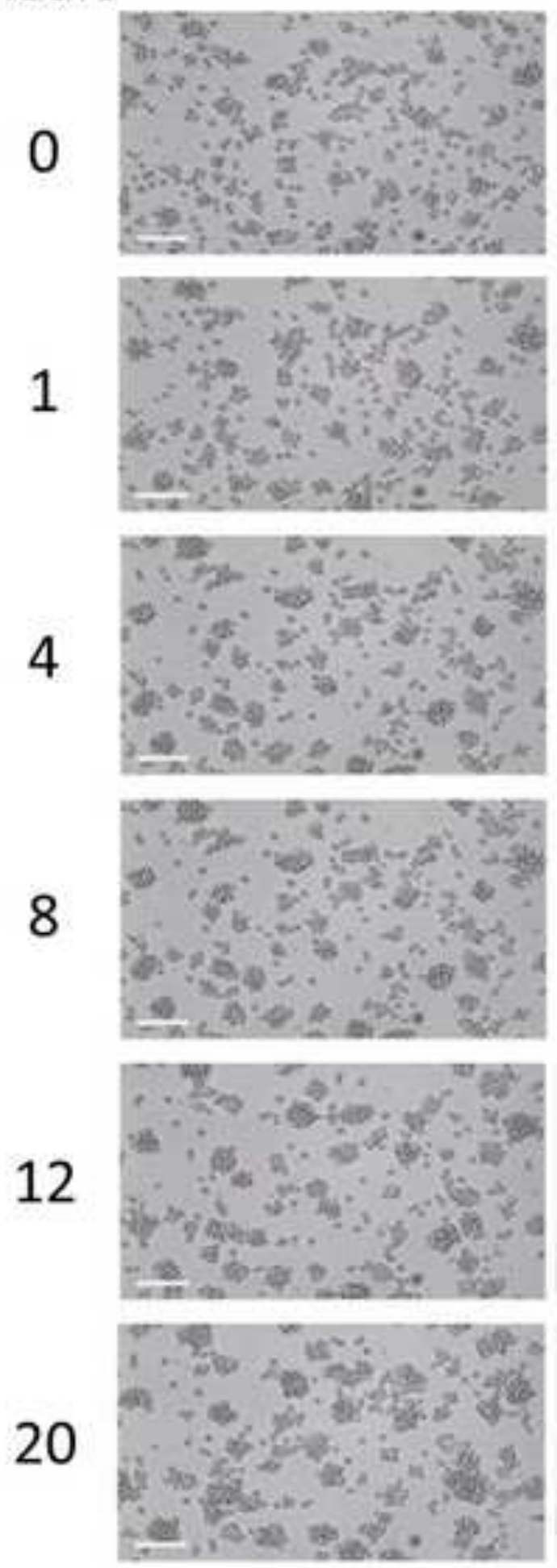

GA101
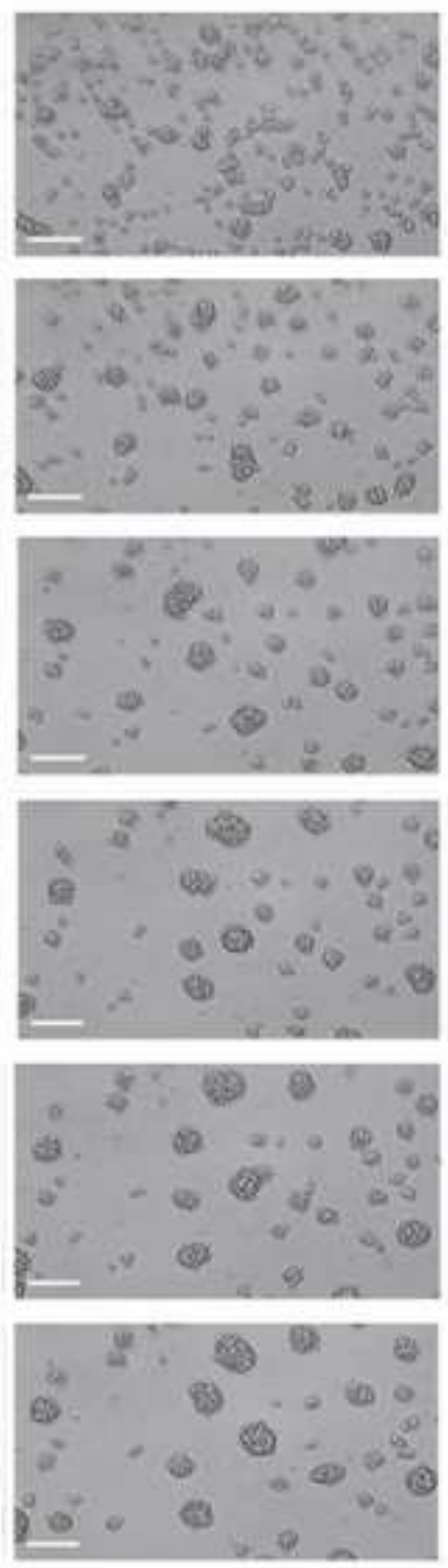

rituximab
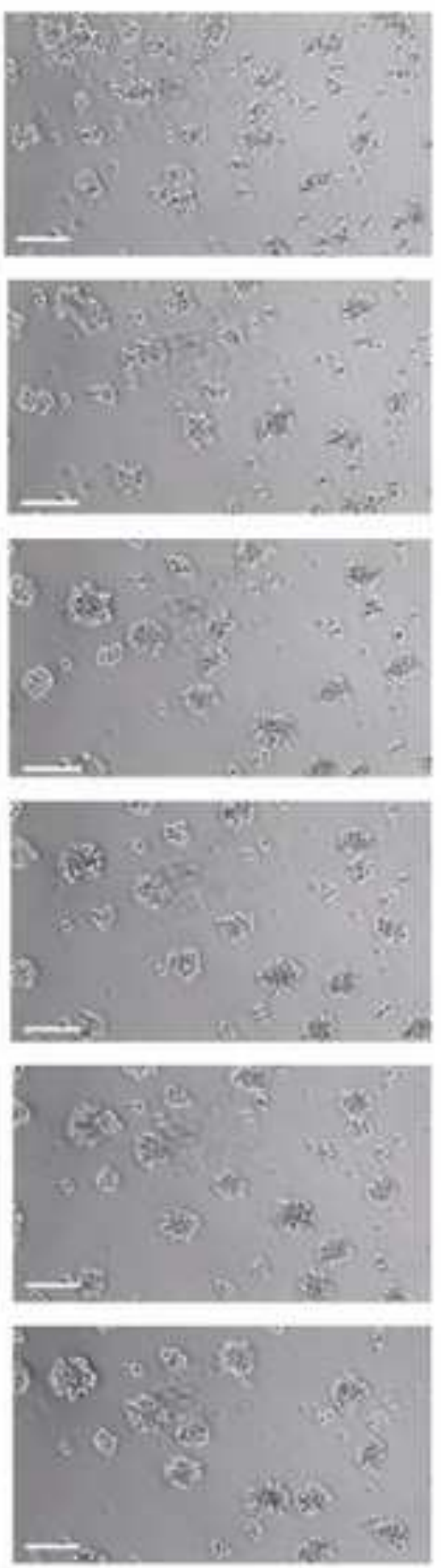
A
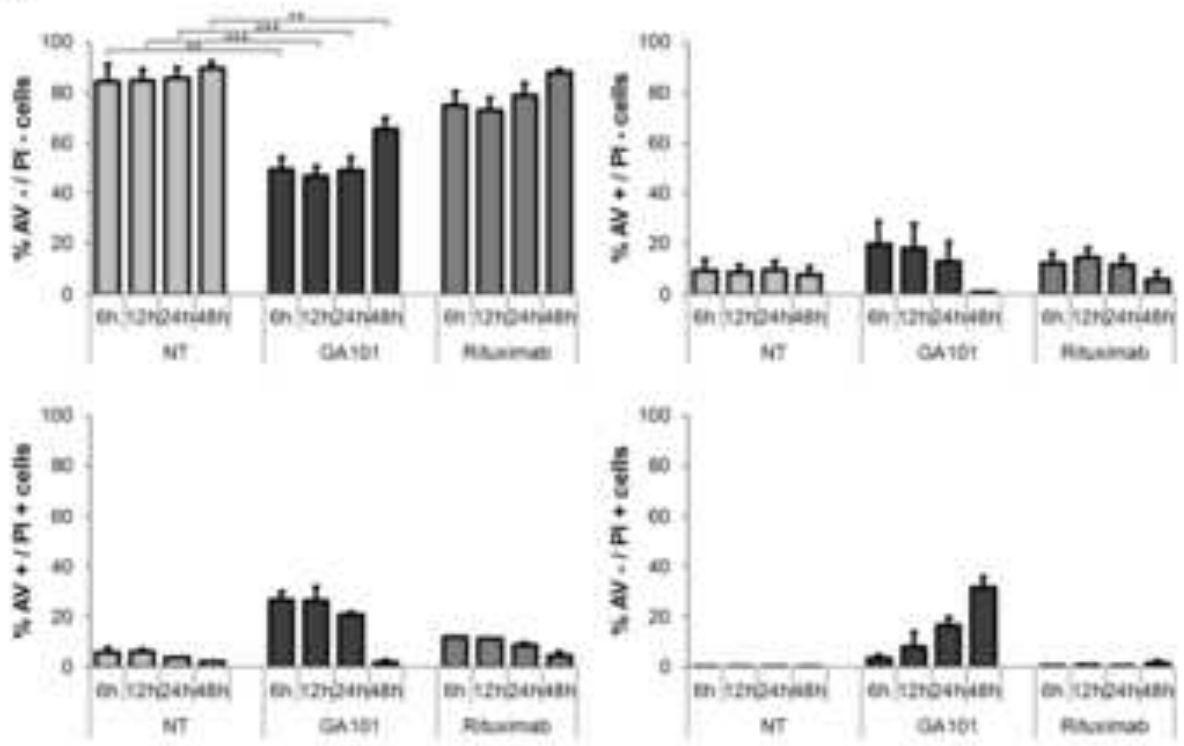

B
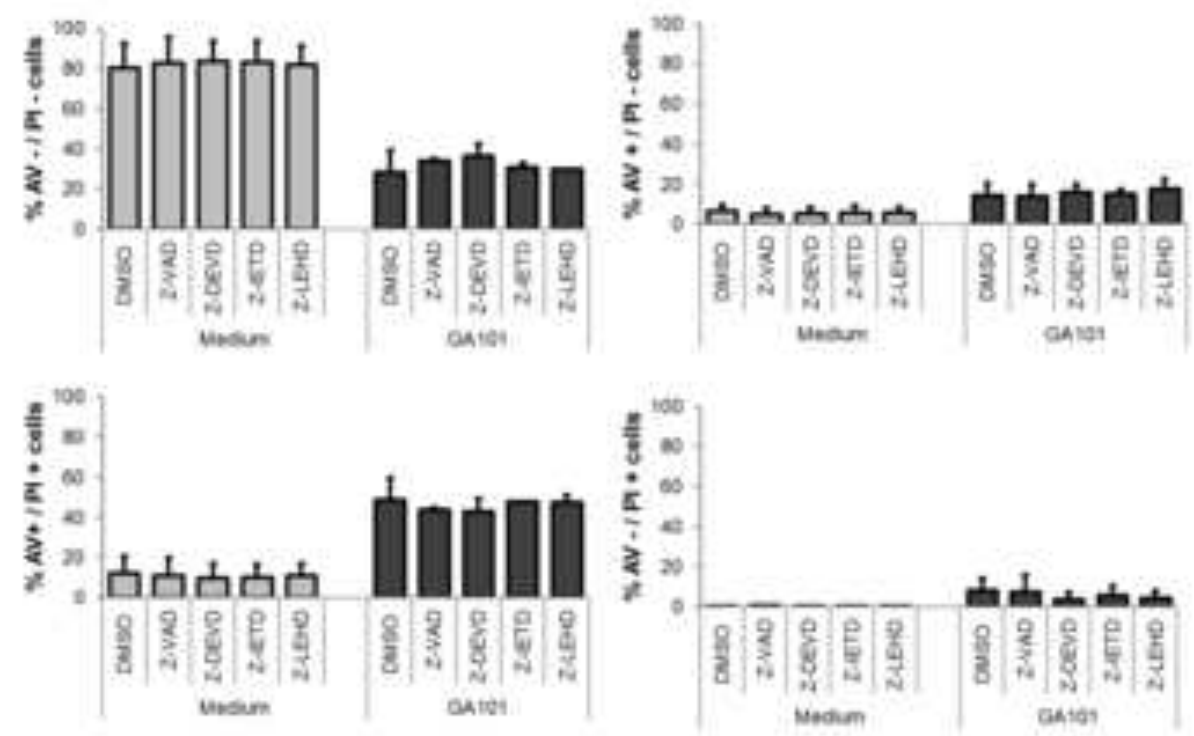

C
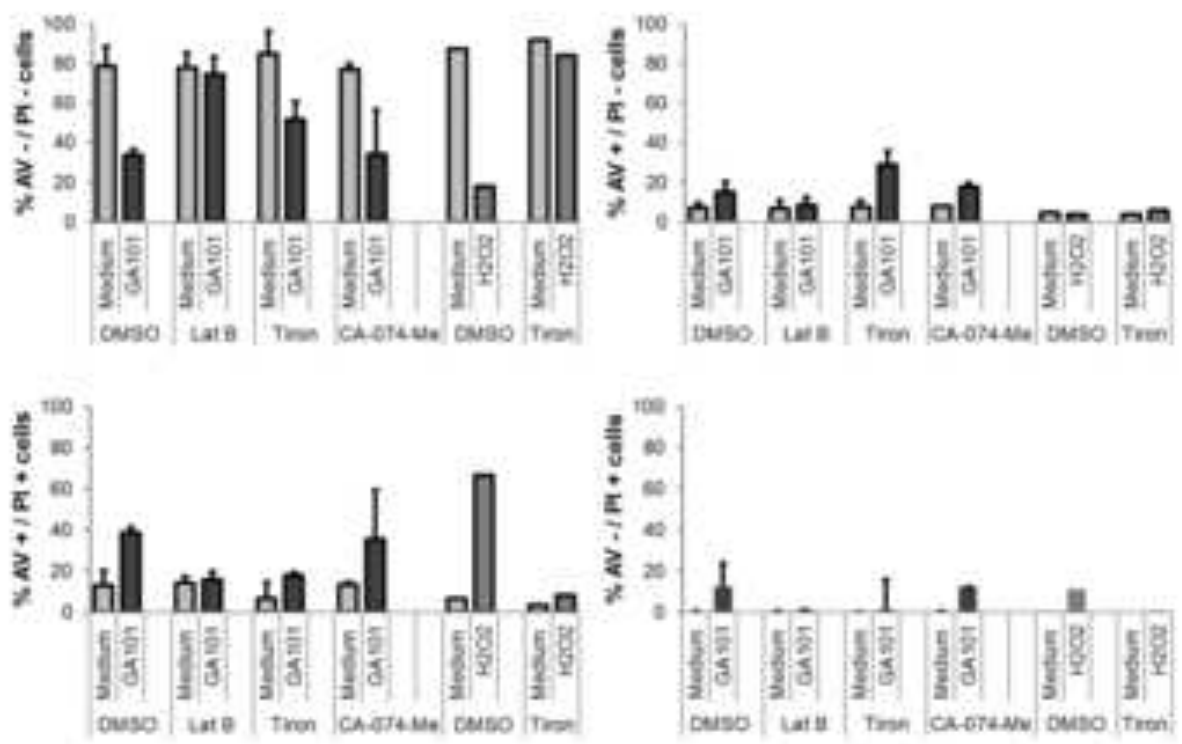
Click here to download high resolution image

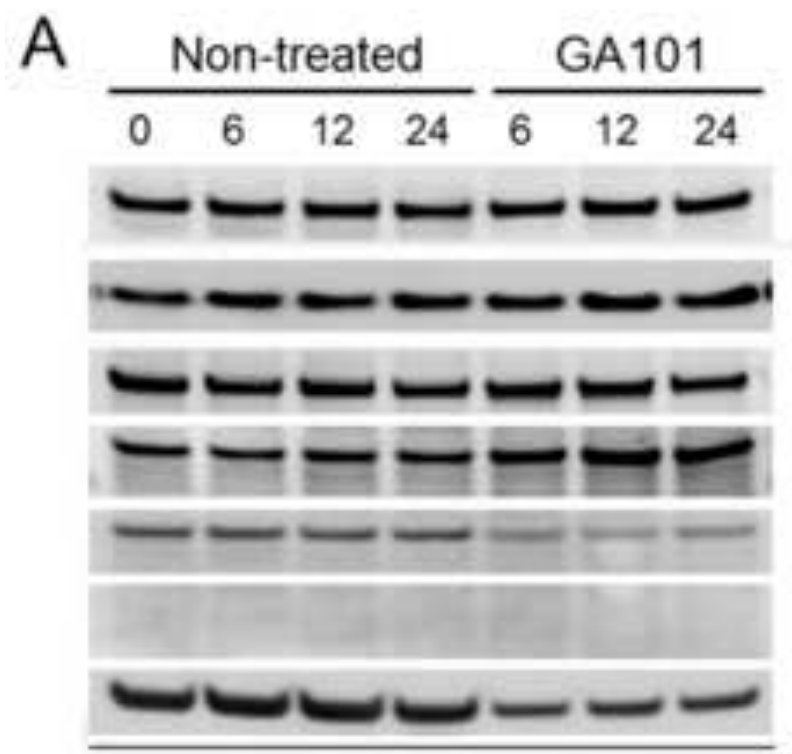

Mito/Lyso fraction

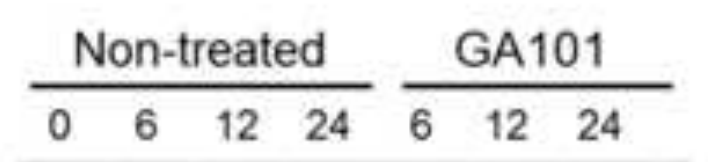

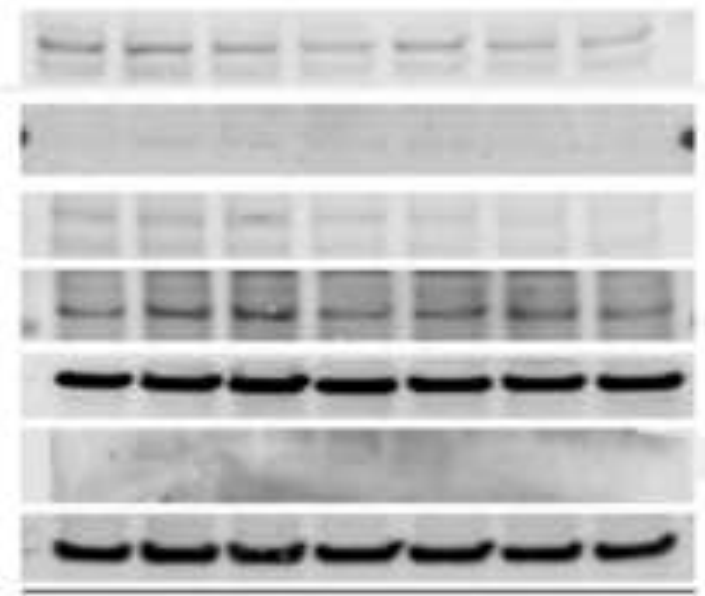

Cytosolic fraction $\leftarrow$ PDK-1 (44 kDa)

$\leftarrow$ cytochrome C (17 kDa)

$\leftarrow$ AlF $(57 \mathrm{kDa})$

$\leftarrow$ endonuclease G (35 kDa)

$\leftarrow$ caspase-3 (35 kDa)

$\leftarrow$ active caspase-3 (17 kDa)

$\leftarrow \beta$-actin (43 kDa)

B

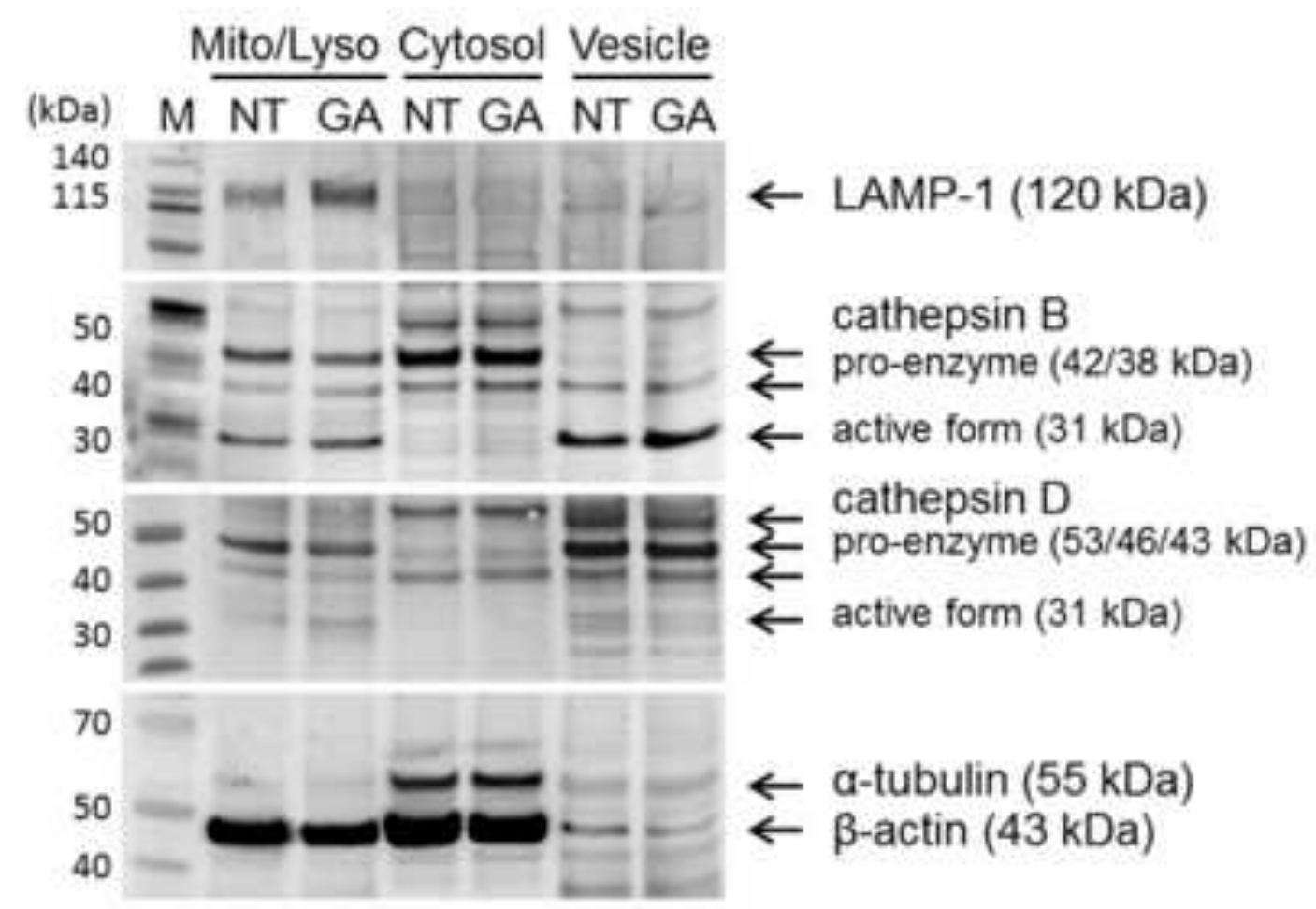


Click here to download high resolution image

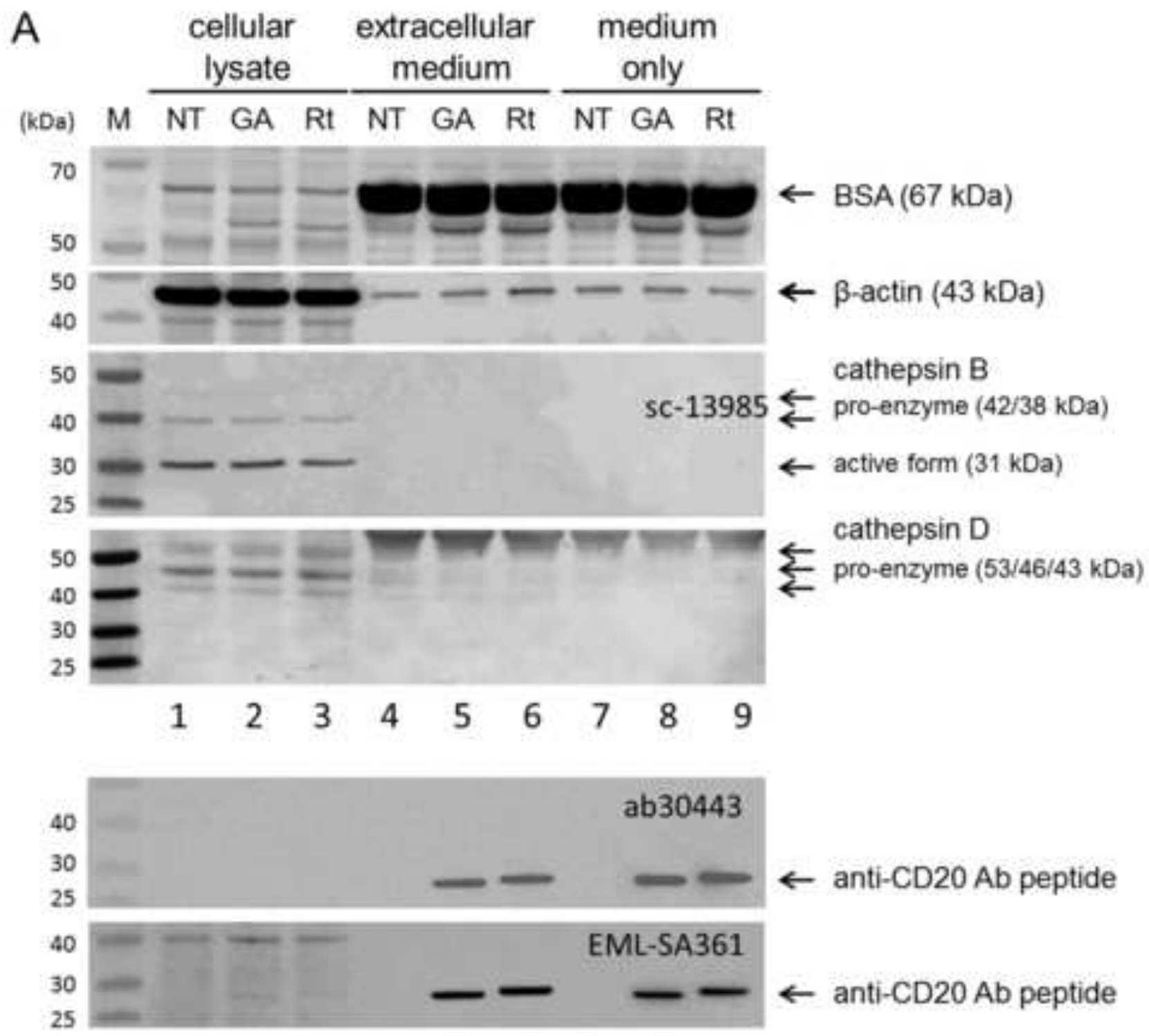

$\begin{array}{lllllllll}1 & 2 & 3 & 4 & 5 & 6 & 7 & 8 & 9\end{array}$

B

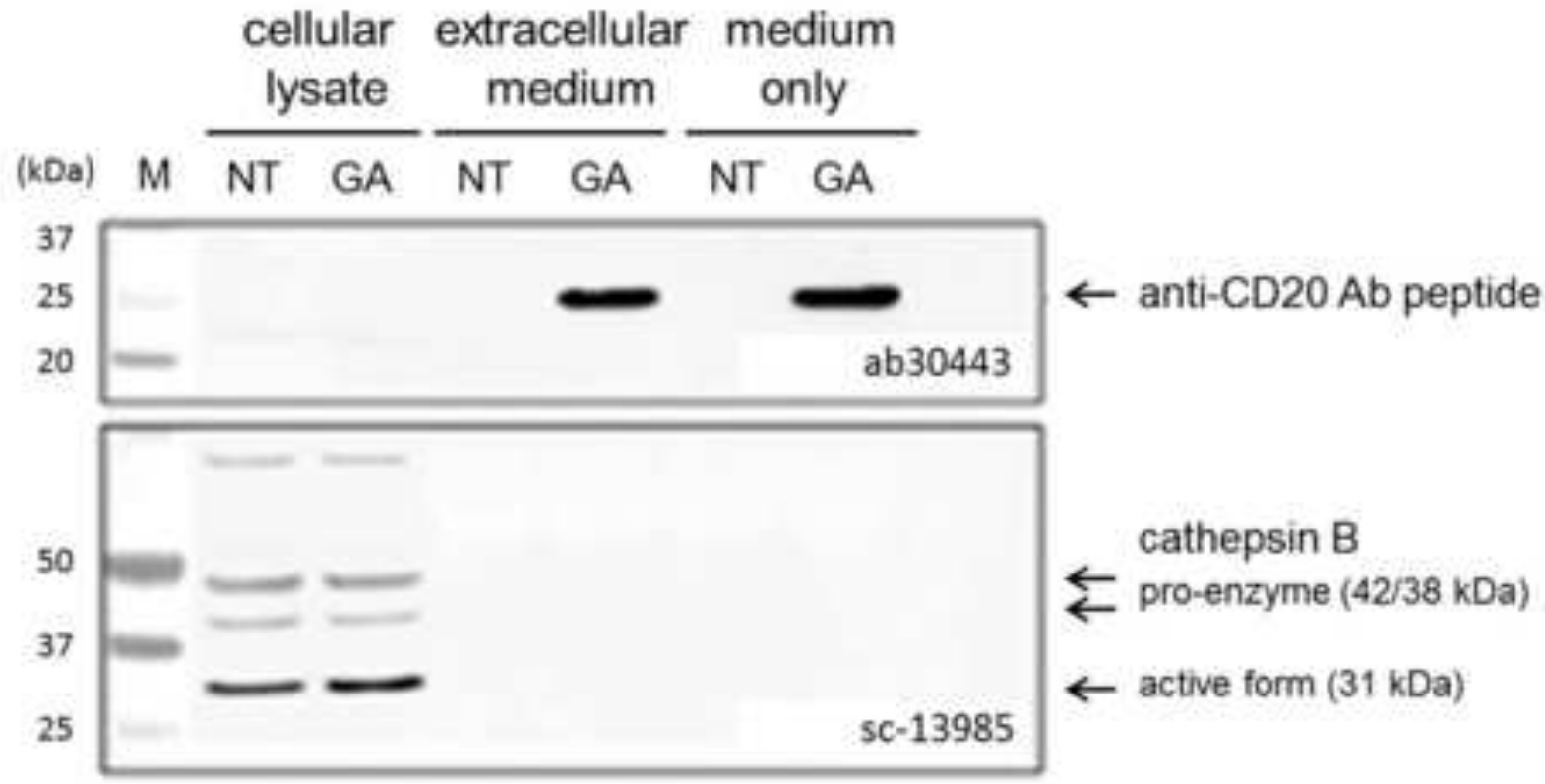


A

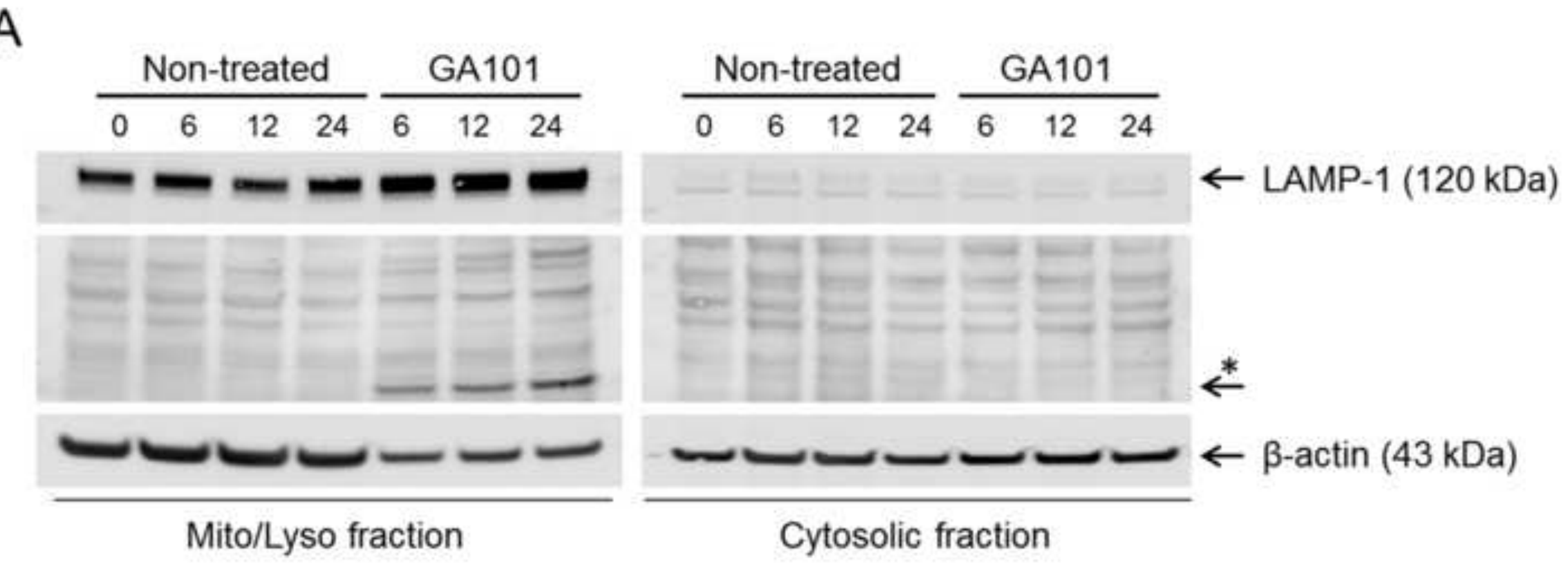

B

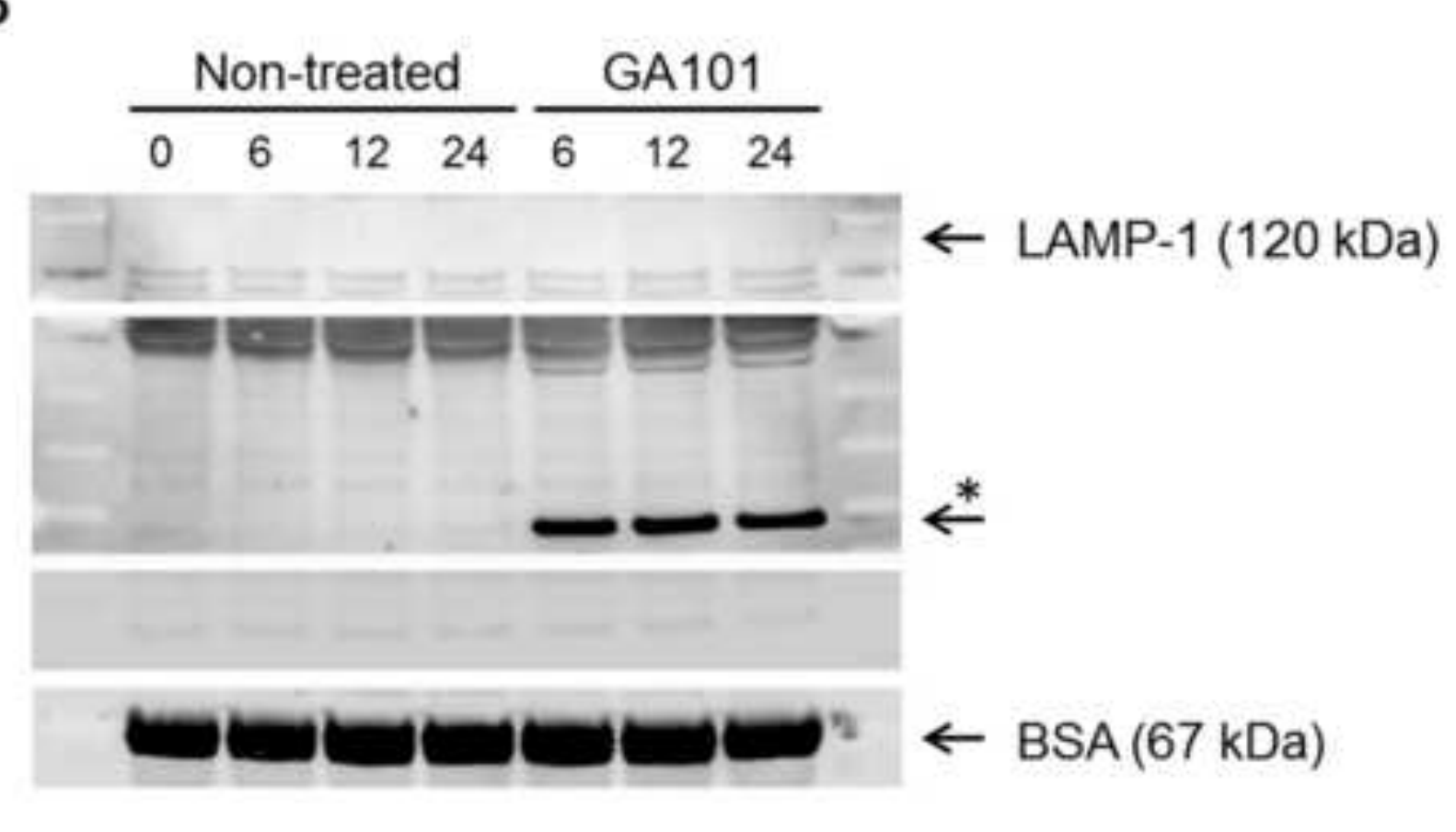

\begin{tabular}{|c|c|c|c|c|c|c|}
\hline \multicolumn{4}{|c|}{ Non-treated } & \multicolumn{3}{|c|}{ GA101 } \\
\hline 0 & 6 & 12 & 24 & 6 & 12 & 24 \\
\hline
\end{tabular}

Mito/Lyso fraction

Cytosolic fraction

\begin{tabular}{|c|c|c|c|c|c|c|}
\hline \multicolumn{4}{|c|}{ Non-treated } & \multicolumn{3}{|c|}{ GA101 } \\
\hline 0 & 6 & 12 & 24 & 6 & 1 & 2 \\
\hline
\end{tabular}

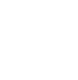


Figure 1: GA101 or rituximab induce homotypic adhesion of Raji cells. Microphotographs of

control cells and cells treated with GA101 or rituximab $(10 \mu \mathrm{g} / \mathrm{ml})$ were taken at $1,4,8,12$ and $20 \mathrm{~h}$ post-treatment using phase contrast videomicroscopy (Objective: 10x, scale bar: $100 \mu \mathrm{m}$ ). Identical experiments were carried out using SUDHL-4 cells leading to similar results (not shown). 
Figure 2: Cell death induced by GA101 is independent of both caspase and cathepsin B activities but involves actin polymerization and ROS production. Flow cytometric analysis of Annexin-V (AV) and propidium iodide (PI) staining of Raji cells. (A) Cells were treated with GA101 or rituximab $(10 \mu \mathrm{g} / \mathrm{ml})$ for $6,12,24$ and $48 \mathrm{~h}$. Untreated cells were prepared at each time point as controls. (B) Cells were incubated with $40 \mu \mathrm{M}$ of broad-spectrum caspase inhibitor (ZVAD-FMK), caspase-3 inhibitor (Z-DEVD-FMK), caspase-8 inhibitor (Z-IETD-FMK) or caspase-9 inhibitor (Z-LEHD-FMK) for $1 \mathrm{~h}$ and then treated with $10 \mu \mathrm{g} / \mathrm{ml}$ of GA101 for $6 \mathrm{~h}$. Cells treated with DMSO were prepared as controls. (C) Cells were pre-treated with $20 \mu \mathrm{M}$ of actin polymerization inhibitor (Latrunculin B, LatB), $20 \mathrm{mM}$ ROS scavenger (Tiron) or $200 \mu \mathrm{M}$ cathepsin B inhibitor (CA-074-Me) for $1 \mathrm{~h}$ and then treated with $10 \mu \mathrm{g} / \mathrm{ml}$ of GA101 or $0.5 \mathrm{mM}$ $\mathrm{H}_{2} \mathrm{O}_{2}$ for $6 \mathrm{~h}$. Cells treated with DMSO were prepared as controls. 
Figure 3: MMP and LMP do not occur following GA101 treatment. (A) Cells were left untreated or treated with $10 \mu \mathrm{g} / \mathrm{ml}$ of GA101 for 6,12 or $24 \mathrm{~h}$, and subcellular fractionation followed by western blot analysis was performed. Abundance of the assayed mitochondrial proteins in the mitochondria/lysosome (Mito/Lyso) fraction and in the cytosolic fraction was analyzed by western blotting. The MW $(\mathrm{kDa})$ of each protein is indicated. At each time point, the abundance of PDK1, cytochrome C, Endonuclease G, and AIF in the Mito/Lyso fraction of GA101-treated Raji cells was similar to that found in the Mito/Lyso fraction of untreated cells. The presence of these proteins only in the Mito/Lyso fraction but not in the cytosolic fraction shows that subcellular fractionation was successful. No significant increase was observed in the quantity of the assayed proteins or in that of active caspase- 3 in the cytosolic fraction of GA101treated Raji cells, compared to controls. Note that actin, which was used as control for equal loading, was less abundant in the Mito/Lyso fraction after GA101 addition. (B) Cells were left untreated or treated with $10 \mu \mathrm{g} / \mathrm{ml}$ of GA101 for $6 \mathrm{~h}$, followed by subcellular fractionation. Abundance of lysosomal-associated membrane protein 1 (LAMP1), cathepsin B (labeled using antibody sc-13985) and cathepsin D in the mitochondria/lysosome (Mito/Lyso) fraction, in the cytosolic fraction and in the vesicle-rich fraction was analyzed by western blot. The MW (kDa) of each protein is indicated. NT: non-treated, GA: GA101. Similar results were obtained using SUDHL-4 cells (not shown). 
Figure 4: Cathepsins B and D are not released into the extracellular medium of cultured B cells after GA101 treatment. Raji cells were left untreated or treated with $10 \mu \mathrm{g} / \mathrm{ml}$ of GA101 or rituximab for $6 \mathrm{~h}$ and cell lysates were prepared. Samples of the extracellular media of cultured cells treated with GA101 or rituximab were prepared as well as samples of pure fresh medium supplemented with GA101 or rituximab. Medium and protein samples were run on acrylamide gels for western blot analysis. (A) Upper panel: membranes were labeled using anti-cathepsin B antibody sc-13985 or anti-cathepsin D antibody. Lower panel: immunoblot using anti-cathepsin antibodies ab30443 or EML-SA361. (B) Jurkat cells were left untreated or were treated with 10 $\mu \mathrm{g} / \mathrm{mL}$ of GA101 for $6 \mathrm{~h}$. Cell lysates and extracellular media were collected for western blot analysis. Pure medium alone and medium containing $10 \mu \mathrm{g} / \mathrm{mL}$ of GA101 were used as controls. Ab30443 antibody displays non-specific reactivity toward GA101. In contrast, sc-13985 antibody specifically recognizes cathepsin B. NT: non-treated, Rt: rituximab, GA: GA101, BSA: bovine serum albumin, a component of fetal bovine serum used in culture medium preparation. The MW $(\mathrm{kDa})$ of each protein is indicated. 
Figure 5: Antibody Ab30443 exhibits non-specific reactivity towards GA101. (A) Raji cells were left untreated or treated with $10 \mu \mathrm{g} / \mathrm{ml}$ of GA101 for $6,12,24 \mathrm{~h}$, followed by subcellular fractionation and western blot analysis. Abundance of the assayed lysosomal proteins in the mitochondria/lysosome (Mito/Lyso) fraction and in the cytosolic fraction was analyzed by western blot. (B) Samples of extracellular media of untreated or GA101-treated cells were collected for western blot analysis. The signal obtained is identical to (A), indicating that ab30443 recognizes the GA101 antibody and not a cellular protein (such as lysosomal Cathepsin B). *: membranes labeled using antibody ab30443. 


\section{${ }^{*}$ Acknowledgements}

\section{Acknowledgments}

This work was supported by grants from Roche Pharma, La Ligue Contre le Cancer (Comité de la Loire) and Institut Carnot CALYM. RJ is a recipient of a CIFRE doctoral fellowship from ANRT. We thank Christian Klein, Roche Innovation Center Zurich for support and critical reading of the manuscript. 
Competing financial interests: AS is employee of Institut Roche. The remaining authors declare no competing financial interests. 


\section{Supplementary Material}

\section{Unexpected cross-reactivity of anti-cathepsin B antibodies leads to uncertainties regarding the mechanism of action of anti-CD20 monoclonal antibody GA101}

Wei Wen Chien ${ }^{a}$, Charlène Niogret ${ }^{\mathrm{a}}$, Romain Jugé ${ }^{\mathrm{a}}$, Loïc Lionnard ${ }^{\mathrm{a}}$, Aurélie Cornut-Thibaut ${ }^{\mathrm{a}}$, Jérôme Kucharczak ${ }^{\mathrm{a}}$, Ariel Savina ${ }^{\mathrm{b} *}$, Gilles Salles ${ }^{\mathrm{a}, \mathrm{c} *}$ and Abdel Aouacheria ${ }^{\mathrm{a}, \mathrm{d} *}$

${ }^{\text {a }}$ Molecular Biology of the Cell Laboratory, Ecole Normale Supérieure de Lyon, UMR 5239 CNRS UCBL - ENS Lyon, 46 Allée d'Italie, 69364 Lyon Cedex 07, France

${ }^{\mathrm{b}}$ Institut ROCHE, 30, cours de l'Ile Seguin, 92650 Boulogne-Billancourt cedex, France

${ }^{\text {c } H o s p i c e s ~ C i v i l s ~ d e ~ L y o n, ~ S e r v i c e ~ d ’ H e ́ m a t o l o g i e, ~} 165$ Chemin du Grand Revoyet, 69495, PierreBénite, France

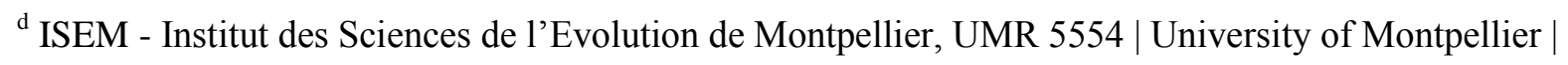
CNRS | IRD | CIRAD | EPHE, Place Eugène Bataillon, 34095 Montpellier, France

* Corresponding author at: ISEM - Institut des Sciences de l'Evolution de Montpellier, UMR 5554 |

University of Montpellier |CNRS | IRD | CIRAD | EPHE, Place Eugène Bataillon, 34095 Montpellier, France

E-mail address: abdel.aouacheria@umontpellier.fr (A. Aouacheria). 


\section{Supplementary Material and Methods}

\section{Protein array}

Cells were treated with GA101 for 1 and $6 \mathrm{~h}$, and then subjected to protein array using PathScan® Stress and Apoptosis Signaling Antibody Array Kit and PathScan® Intracellular Signaling Array Kit (Cell Signaling), according to manufacturer's instruction. In brief, GA101-treated cells were lysed in $100 \mu \mathrm{l}$ of PathScan Sandwich ELISA lysis buffer (Cell Signaling) containing ETDA-free anti-protease cocktail (Roche). The supernatants were collected after a centrifugation at $14000 \mathrm{~g}$ for 2 min. Array slides were incubated in blocking buffer for $15 \mathrm{~min}$. Lysate $(75 \mu \mathrm{l}, 0.6 \mathrm{mg} / \mathrm{ml})$ was dispensed into wells of array slide for overnight incubation at $4^{\circ} \mathrm{C}$. Incubation in Detection Antibody Cocktail solution $(75 \mu \mathrm{l})$ for 1.5h and in HRP-linked Streptavidin solution $(75 \mu \mathrm{l})$ for 45 min was then sequentially performed. Labeled proteins were detected by chemiluminescence using LumiGIO/Peroxide solution and recorded with LAS3000 software (Fujifilm). Spot intensities were analyzed using ImageJ Software.

\section{Membrane protein extraction}

$5 \times 10^{6}$ cells were harvested $4 \mathrm{~h}$ after treatment with GA101 by centrifugation at $300 \mathrm{~g}$ for $5 \mathrm{~min}$. Untreated cells were used as controls. Cell pellets were washed with $3 \mathrm{~mL}$ of Cell Wash Solution (Membrane Protein Extraction kit, Thermo scientific) and centrifuged at 300g for 5 min. Supernatants were carefully removed and discarded. Cells were resuspended in $1.5 \mathrm{~mL}$ of Cell Wash Solution and transferred to a $2 \mathrm{~mL}$ centrifuge tube. Cells were centrifuged at $300 \mathrm{~g}$ for $5 \mathrm{~min}$ and supernatants were discarded. $0.75 \mathrm{~mL}$ of Permeabilization Buffer (Membrane Protein Extraction kit, Thermo scientific) was added to the cell pellets. Cell suspension was then incubated $10 \mathrm{~min}$ at $4{ }^{\circ} \mathrm{C}$ with constant mixing. After incubation, cells were centrifuged for $15 \mathrm{~min}$ at $16000 \mathrm{~g}$. Supernatants containing cytosolic proteins were transferred into a new 
tube. $0.5 \mathrm{~mL}$ of Solubilization buffer (Membrane Protein Extraction kit, Thermo scientific) was added to the pellets in order to resuspend the cells. Tubes were then incubated at $4^{\circ} \mathrm{C}$ for $30 \mathrm{~min}$ with constant mixing. After incubation, cells were centrifuged at $16000 \mathrm{~g}$ for $15 \mathrm{~min}$ at $4^{\circ} \mathrm{C}$. Supernatants containing solubilized membrane and membrane-associated proteins were collected into a new tube. The quantity of proteins in samples was estimated by Bradford assay using a Multiskan Spectrum plate reader at 595nm (Thermo Electro Corporation) and western blotting was performed.

\section{Western blotting}

Total cell lysates were prepared using RIPA lysis buffer containing ETDA-free anti-protease cocktail. The quantity of proteins in samples was estimated by Bradford assay. For SDS-

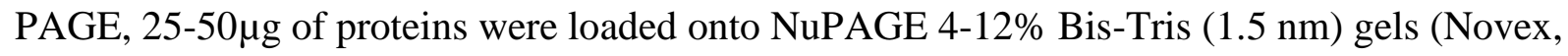
Life Technologies). Fractionation of cellular proteins was performed using MES buffer (Life technologies) at $200 \mathrm{~V}$ for $40 \mathrm{~min}$. Protein transfer was performed using iBlot Gel Transfer Stacks (nitrocellulose mini, Life Technologies). The protein bands were detected by chemiluminescence using Lumina Forte reagent (Millipore) and recorded with LAS3000 software (Fujifilm).

\section{Immunocytochemistry}

Cells were spun on glass slides by centrifugation at 650rpm for 5min. Fixed cells were dried overnight at room temperature and stored at $-20^{\circ} \mathrm{C}$. Fixation and permeabilization were performed using $4 \%$ paraformaldehyde (at room temperature) and acetone $\left(-20^{\circ} \mathrm{C}\right)$ for $10 \mathrm{~min}$, respectively, followed by incubation in blocking buffer (5\% BSA in PBS) overnight at $4{ }^{\circ} \mathrm{C}$ with gentle agitation. The cells were then labeled using mouse anti-LAMP-1 (ab25630, Abcam) and rabbit anti-cathepsin B antibody (sc-13985 from Santa-Cruz or ab30443 from Abcam) at room temperature for $1 \mathrm{~h}$, followed by incubation with donkey anti-mouse- 
Alexa568 (Invitrogen) and goat anti-rabbit-Alexa488 (Invitrogen) secondary antibodies, before a final wash in PBS containing 0.2\% Tween-20. Fluorescence imaging microphotographs were taken using an Axiophot Zeiss epifluorescence microscope. 


\section{$\underline{\text { Supplementary Figures }}$}

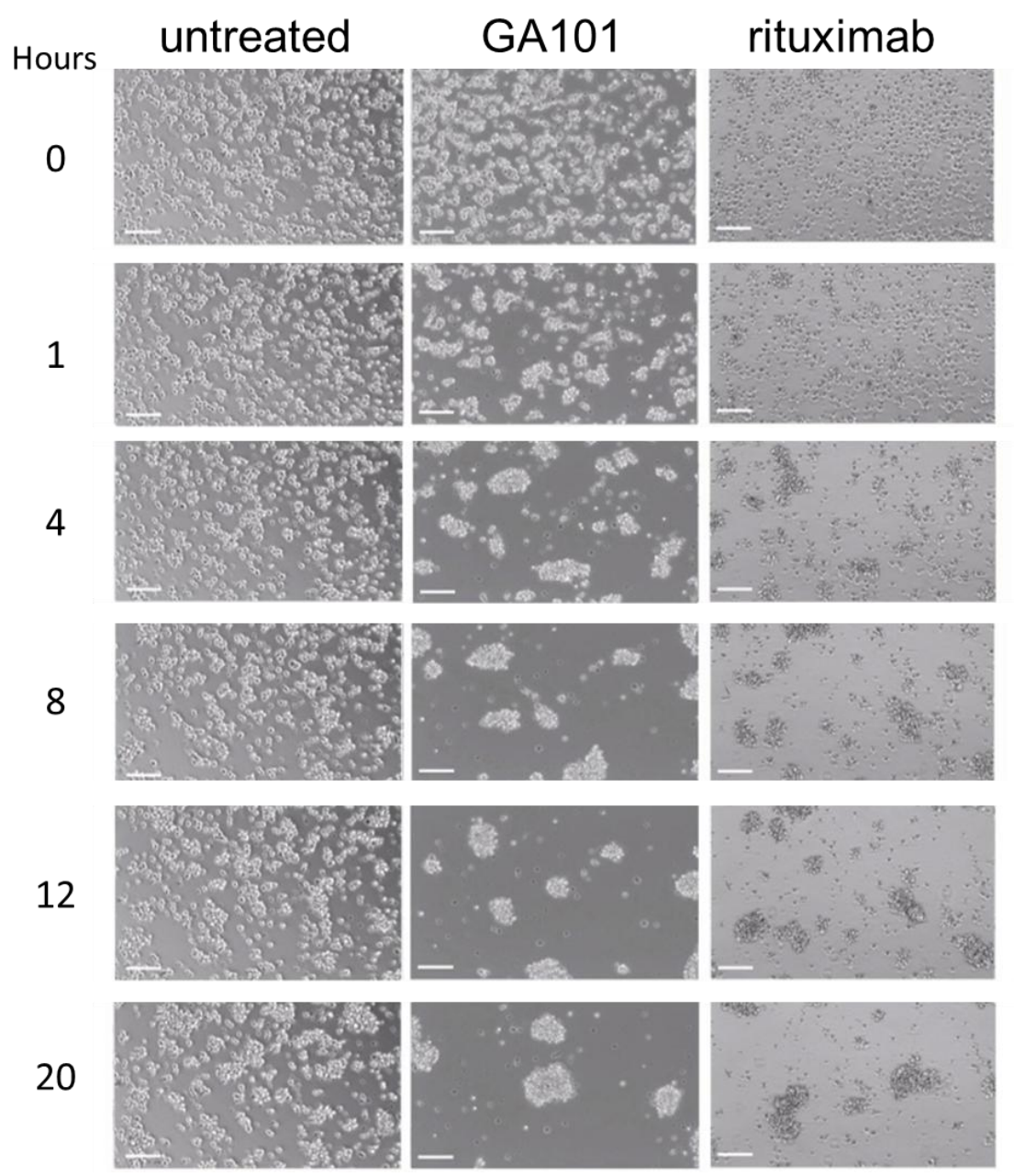

Supplementary Figure 1: Homotypic adhesion of SUDHL-4 cells induced by GA101 or

Rituximab. Microphotographs of untreated SUDHL-4 cells and cells treated with GA101 or Rituximab $(10 \mu \mathrm{g} / \mathrm{ml})$ were taken at $1,4,8,12$ and $20 \mathrm{~h}$ post-treatment using phase contrast microscopy (Objective: 10x, scale bar: $100 \mu \mathrm{m}$ ). 

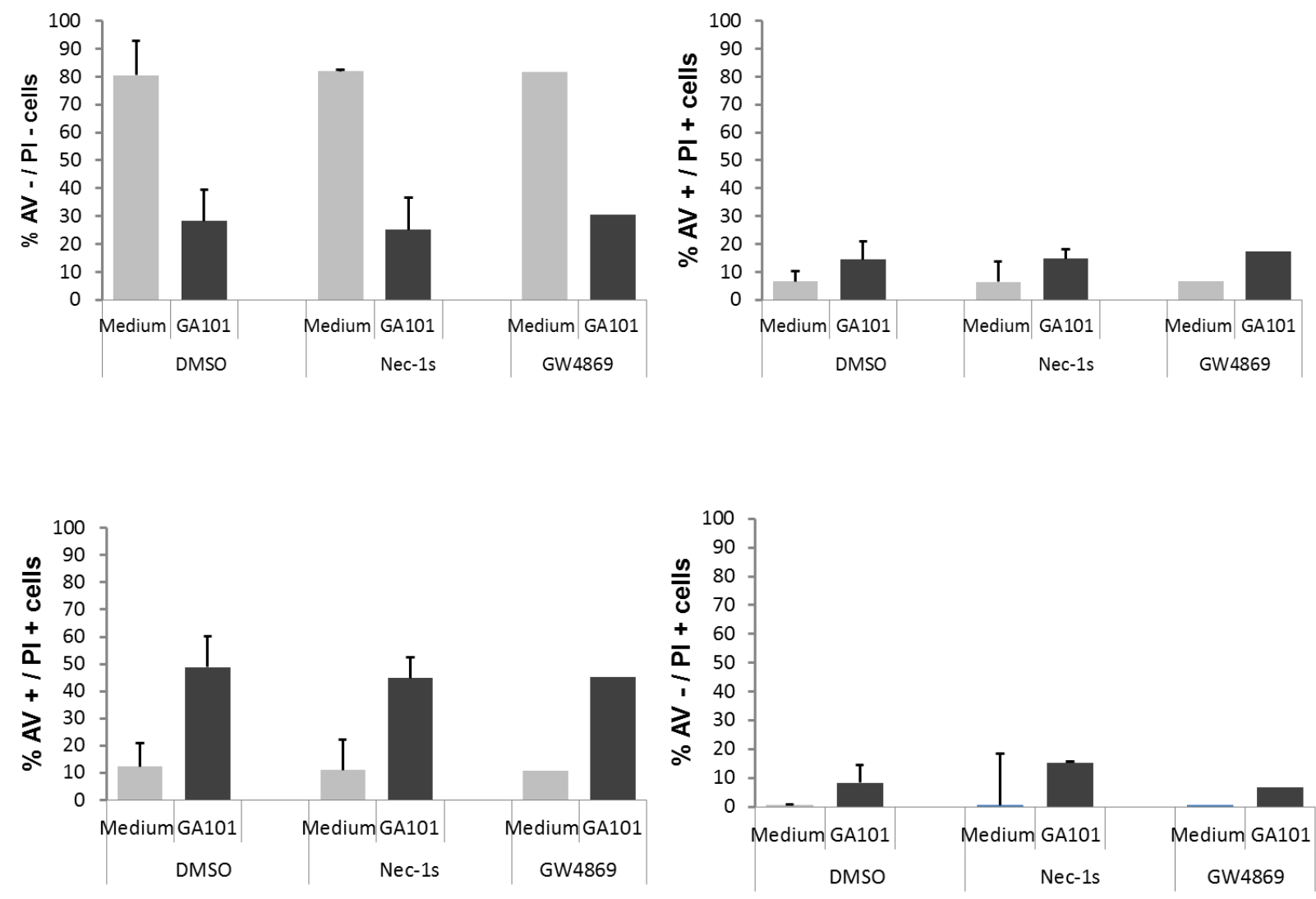

Supplementary Figure 2: Chemical inhibition of RIPK1 and sphingomyelinase does not prevent cell death after GA101 exposure. Raji cells were incubated in presence of $20 \mu \mathrm{M}$ of RIPK inhibitor (Nec-1s) or $2 \mu \mathrm{M}$ of sphingomyelinase inhibitor (GW4869) for $1 \mathrm{~h}$ and then treated with $10 \mu \mathrm{g} / \mathrm{ml}$ of GA101 for $6 \mathrm{~h}$. Cells treated with DMSO were prepared as controls. Treated cells were analyzed by flow cytometry after dual Annexin V (AV) - Propidium iodide (PI) staining. 


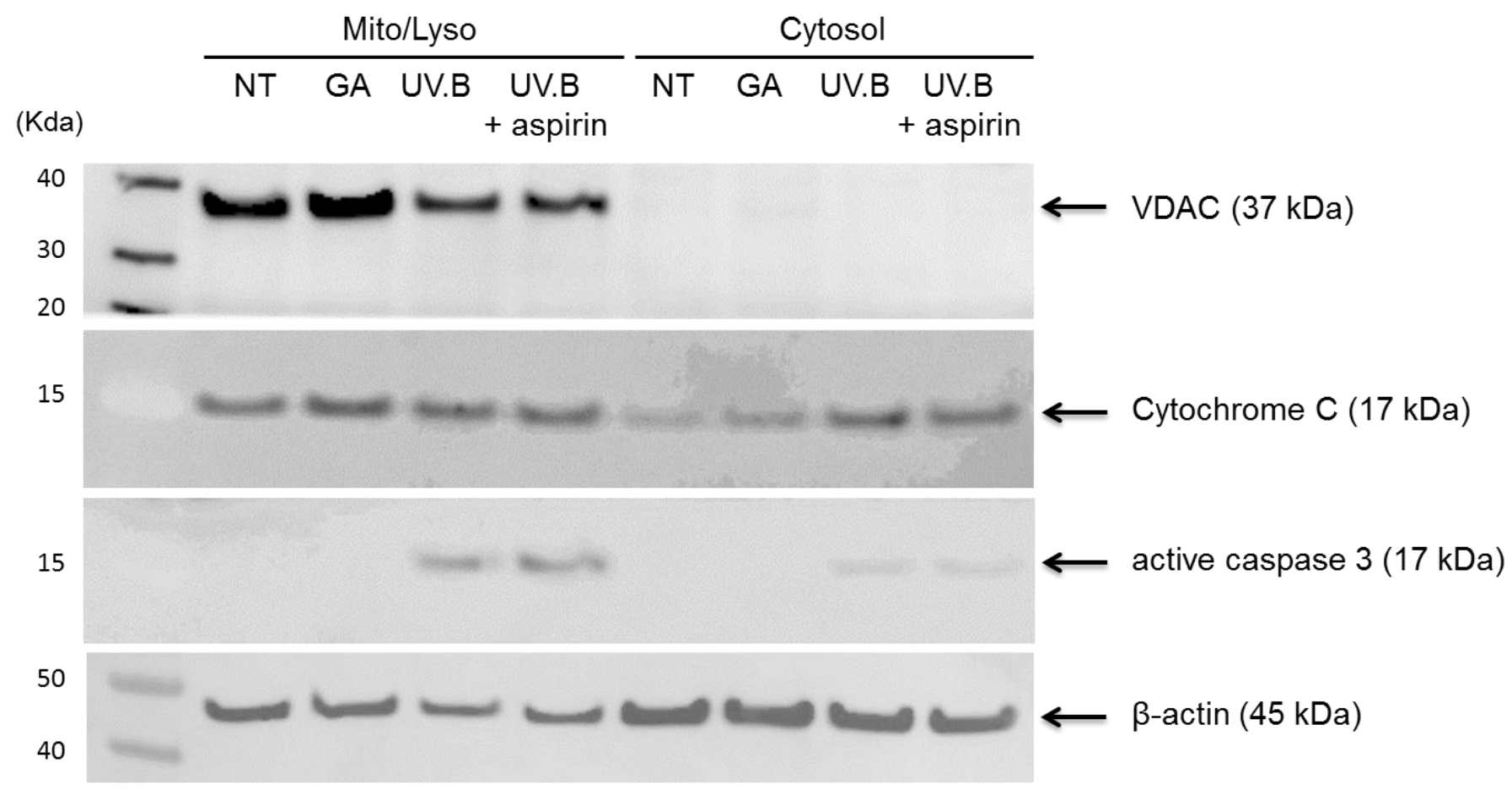

Supplementary Figure 3. Cytosolic release of Cytochrome $C$ and caspase-3 activation are detectable in UVB-treated Raji cells.

Cells were left untreated or treated with $10 \mu \mathrm{g} / \mathrm{ml}$ of GA101 for $16 \mathrm{~h}$ and subcellular fractionation was then performed. Cells exposed to $50 \mathrm{~mJ} / \mathrm{cm}^{2} \mathrm{UVB}$ with or without $10 \mathrm{mM}$ aspirin (Pique et al., 2000) were prepared as a positive control for apoptosis induction. Abundance of the assayed mitochondrial proteins in the mitochondria/lysosome (Mito/Lyso) fraction and in the cytosolic fraction was analyzed by western blotting. The MW (kDa) of each protein is indicated. VDAC is a mitochondrial membrane protein. The results indicate that in contrast to cells treated with GA101, cytosolic release of cytochrome C and cleavage of caspase-3 are observed in cells challenged with UBV or aspirin. 


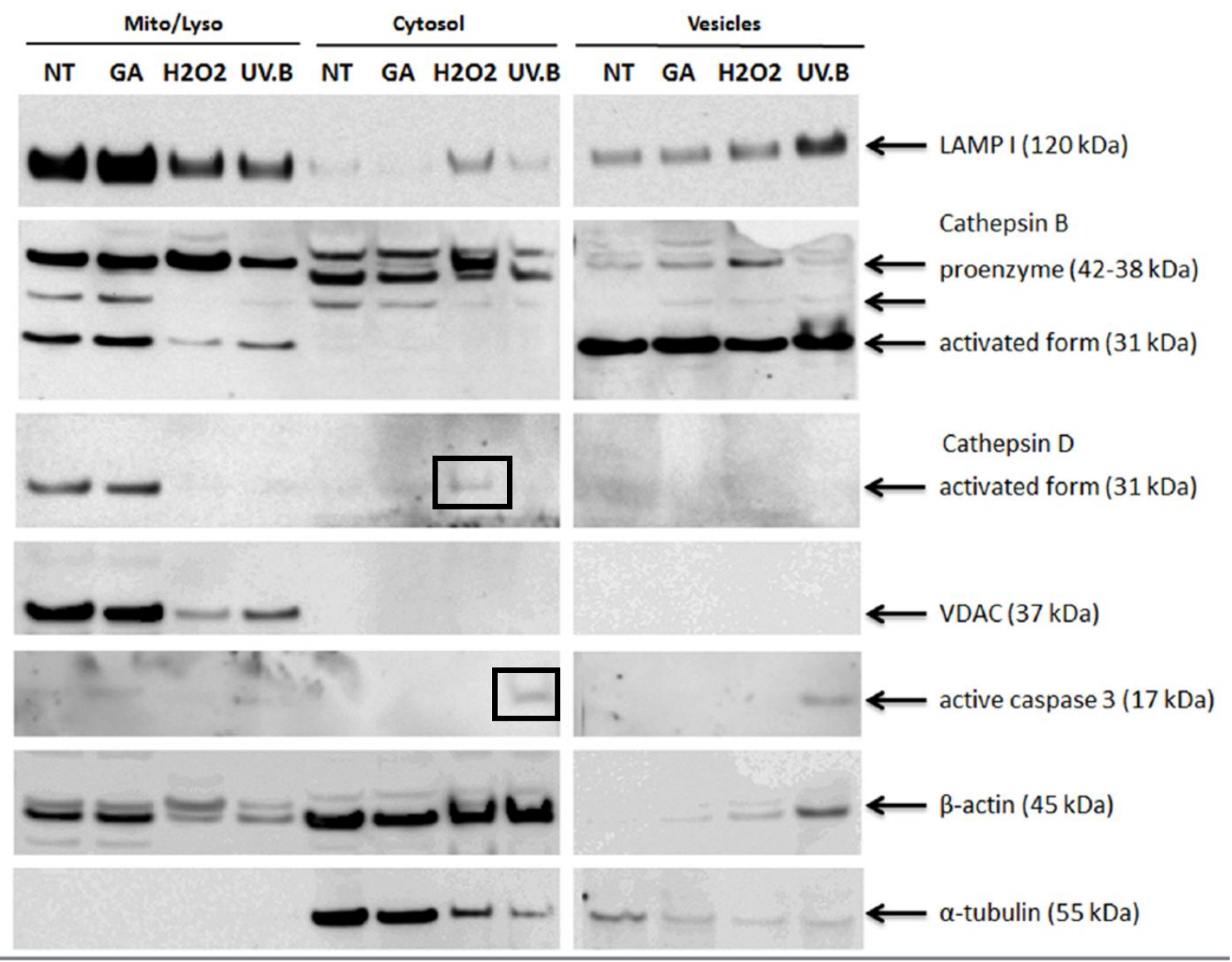

Supplementary Figure 4. Detection of cathepsin release in $\mathrm{H}_{2} \mathrm{O}_{2}$-treated cells.

Raji cells were left untreated or treated with $10 \mu \mathrm{g} / \mathrm{ml}$ of GA101 or $0.05 \mathrm{mM} \mathrm{H}_{2} \mathrm{O}_{2}$ for $16 \mathrm{~h}$, followed by subcellular fractionation. Abundance of lysosomal-associated membrane protein 1 (LAMP1), cathepsin B (labeled using antibody sc-13985) and cathepsin D in the mitochondria/lysosome (Mito/Lyso) fraction, in the cytosolic fraction and in the vesicle-rich fraction was analyzed by western blot. The MW $(\mathrm{kDa})$ of each protein is indicated. NT: nontreated, GA: GA101. The presence of active cathepsin B and D proteins only in the Mito/Lyso fraction but not in the cytosol shows that LMP does not occur in response to GA101 treatment. $\mathrm{H} 2 \mathrm{O} 2$ and UVB were used as positive controls for LMP and MMP respectively and produced 
the expected outcome: cytosolic release of cathepsin D (see box in lane 7) and of active caspase-3 (box in lane 8), respectively. 

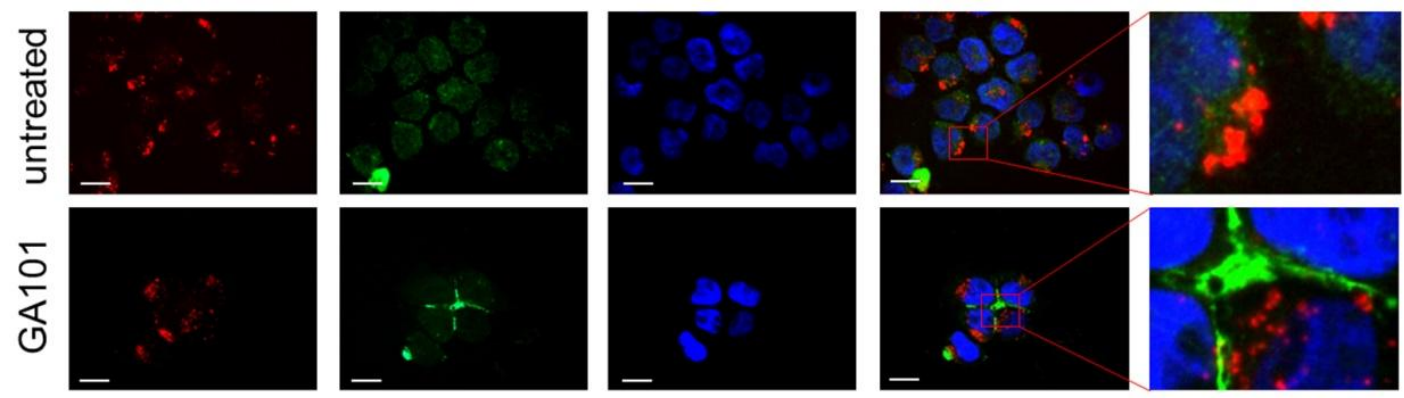
$\alpha-$ LAMP-1
$\alpha-a b 30443$

DAPI
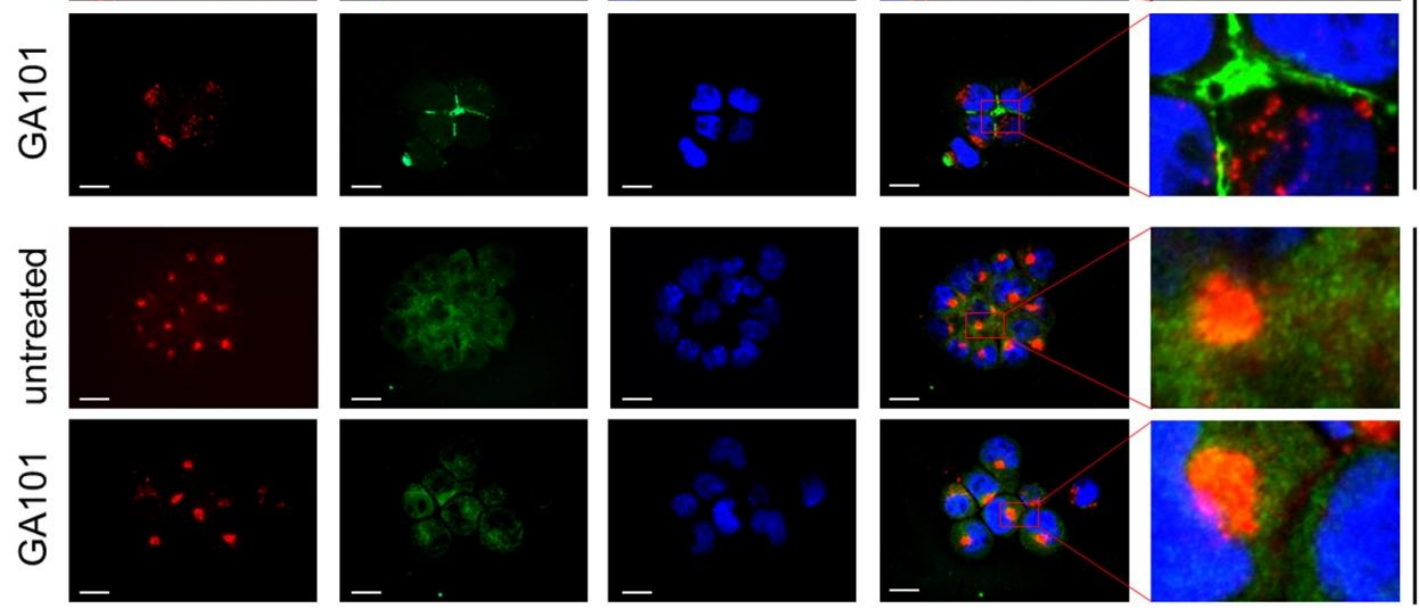
$\alpha-$ LAMP-1 $\alpha-\mathrm{SC}-13985$
DAPI

\section{Supplementary Figure 5: Immunocytochemical staining using anti-cathepsin B}

antibodies ab30443 and sc-13985. Untreated and GA101-treated cells were cytospinned and subsequently subjected to immunofluorescent labeling using an antibody directed against the lysosomal marker LAMP1 (red) and either ab30443 or sc-13985 (green), two antibodies produced to detect cathepsin B. The nucleus was stained using DAPI (blue).

Microphotographs of labeled cells were taken under an Axiophot Zeiss epifluorescence microscope (Objective: 50 x Oil, scale bar: $15 \mu \mathrm{M}$ ). These immunofluorescence data strongly suggest that ab30443 (as well as EML-SA36, see Supplementary Figure 6) recognizes GA101 itself, either localized at the cell surface after CD20 ligation or in the pericortical or subplasmalemmal region as a consequence of its cellular internalization. Note that staining was brighter at cell-cell junctions, suggesting that GA101-CD20 complexes actively participate to the HA process. 


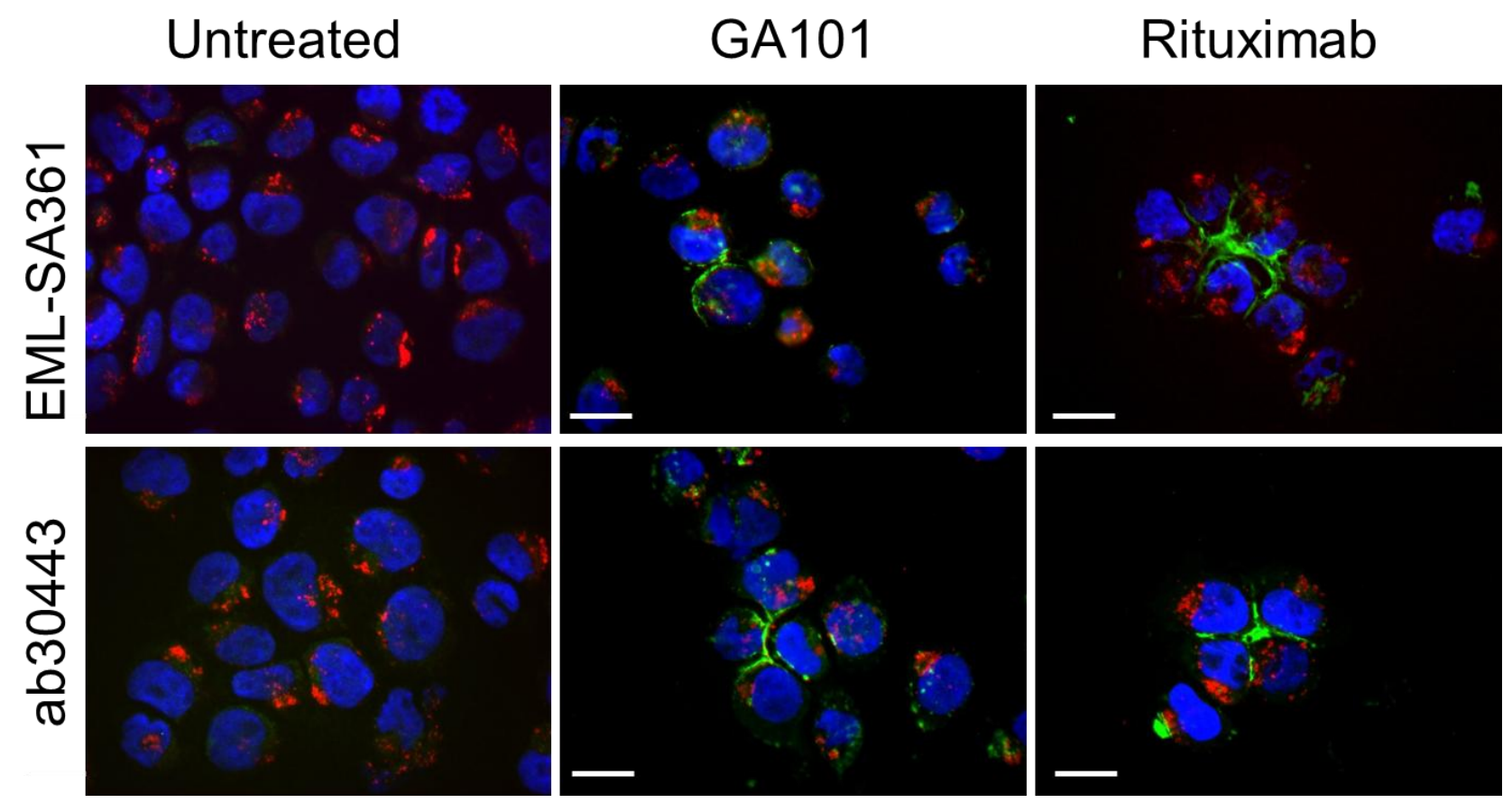

Supplementary Figure 6: Immunofluorescent labeling using the EML-SA361 antibody. Untreated and GA101-treated cells were cytospinned and subsequently subjected to immunofluorescent labeling using an antibody directed against the lysosomal marker LAMP1 (red) and either EML-SA361 or ab30443 (green), two antibodies produced to detect cathepsin B. The nucleus was stained using DAPI (bleu). Microphotographs of labeled cells were taken under an Axiophot Zeiss epifluorescence microscope (Objective: 50 x Oil, scale bar: $15 \mu \mathrm{M})$. 

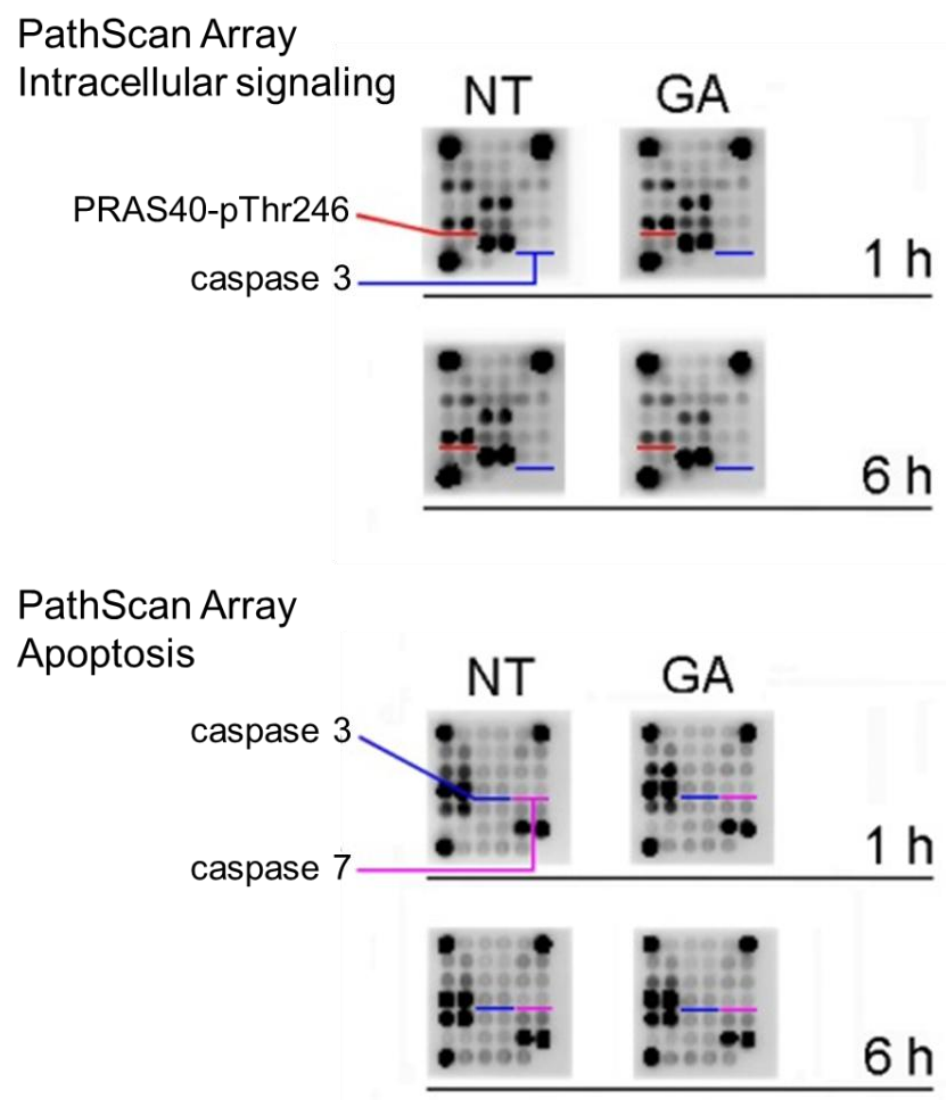

Supplementary Figure 7. The activation status of major signaling and apoptotic molecules remains stable upon GA101 exposure. Raji cells were left untreated or treated with $10 \mu \mathrm{g} / \mathrm{ml}$ of GA101 for 1 and $6 \mathrm{~h}$. Total cell lysates were prepared and subjected to intracellular signaling and apoptosis protein arrays using the PathScan ${ }^{\circledR}$ Intracellular and Apoptosis Signaling Antibody Array Kits. The expression of total or phosphorylated proteins was visualized using a chemiluminescent method. One negative (left-bottom) and three positive controls were set in the 4 corners of each membrane. NT: non-treated, GA: GA101. The pathways studied were: (1) MAPK-MEK/ERK (Erk1/2-Thr202/Tyr204); (2) MAPKp38/JNK (TAK-Ser412, p38-Thr180/Tyr182, SAPK/JNK-Thr183/Tyr185; HSP27-Ser78); (3) Jak/Src (Stat1/3-Tyr701/Try705); (4) mTORC1 (S6 ribosomal protein-Ser235/236, p70 S6 kinase-Thr389); (5) mTORC2 (Akt-Thr308/Ser473, PRAS40-Thr246, Bad-Ser112/Bad136, GSK-3-Ser9); (6) AMPK (AMPK $\alpha$-Thr172); (7) ATM/ATR (p53-Ser15, Chk1/Chk2Ser345/Thr68; Smad2-Ser465/467); (8) caspase (caspase-3/7 and PARP cleavage; Survivin); 


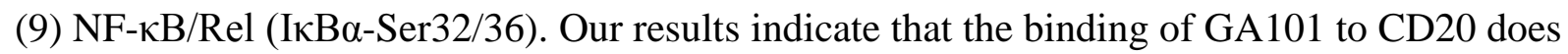
not provoke a significant modification in the assayed signaling pathways. Only Thr246phosphorylated PRAS40 was reduced (by $~ 30 \%$ ) in GA101-treated cells $6 \mathrm{~h}$ after treatment. Of note, activation of caspases -3 and -7 was not detected in GA101-treated cells, confirming that GA101-induced cell death is caspase-independent. 
A

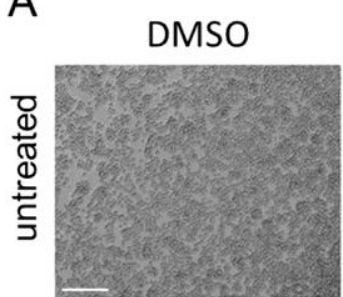

Lat B

ML141

DPI

TIRON
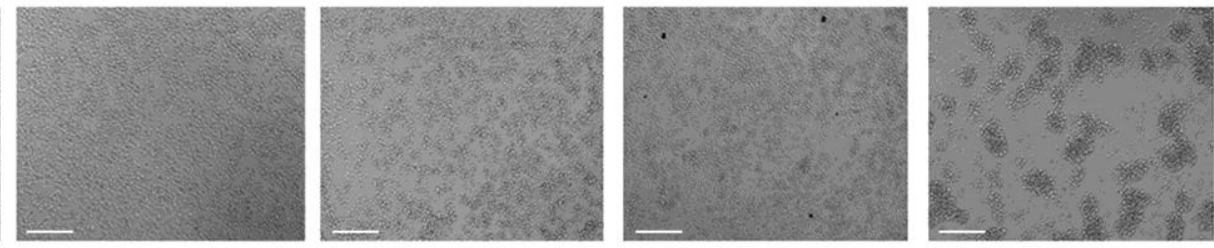

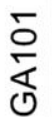
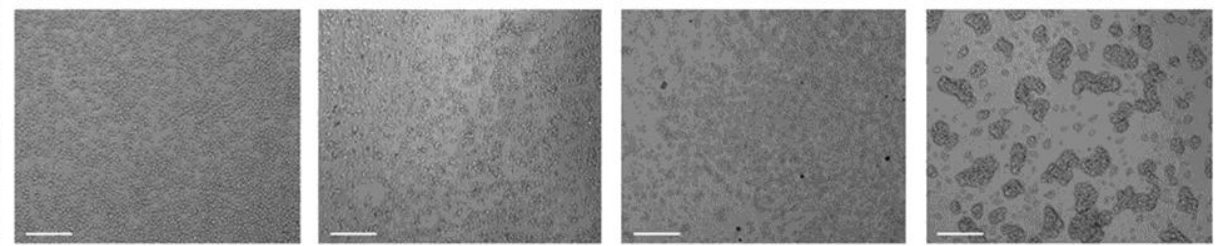

B
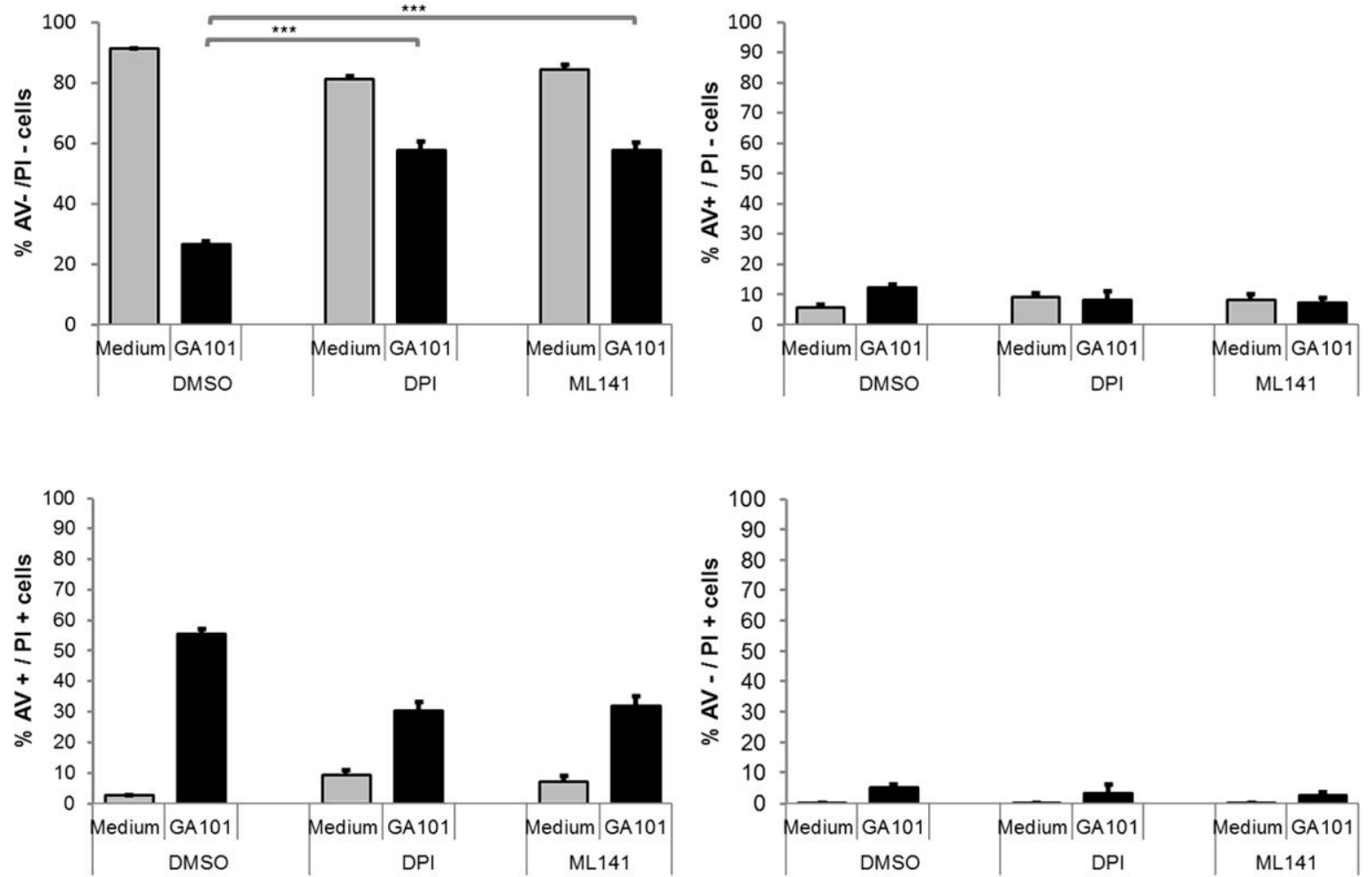

C
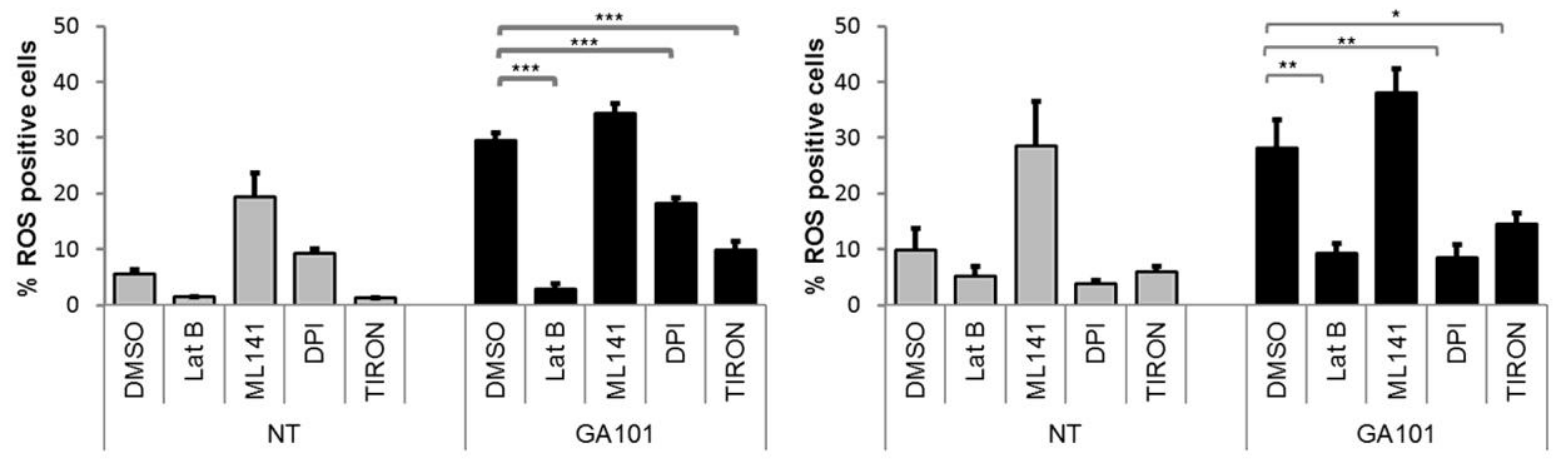


\section{Supplementary Figure 8: Involvement of Cdc42 GTPase and NOX activities in HA, ROS}

production and cell death induced in response to GA101. (A) Raji cells were incubated in presence of $20 \mu \mathrm{M}$ of actin polymerization inhibitor (Latrunculin B, LatB), $20 \mathrm{mM}$ of ROS scavenger (Tiron), $150 \mu \mathrm{M}$ of NOX inhibitor DPI or $160 \mu \mathrm{M}$ of cdc42 GTPase inhibitor ML141 for $2 \mathrm{~h}$ and then treated with $10 \mu \mathrm{g} / \mathrm{ml}$ of GA101 for $6 \mathrm{~h}$. Cells treated with DMSO were prepared as controls. Microphotographs were taken using an inverted Leica microscope (objective: 10x, scale bar: $100 \mu \mathrm{m}$ ). (B) Raji cells were incubated in presence of $150 \mu \mathrm{M}$ of NOX inhibitor DPI or $160 \mu \mathrm{M}$ of Cdc42 GTPase inhibitor ML141 for $2 \mathrm{~h}$ and then treated with $10 \mu \mathrm{g} / \mathrm{ml}$ of GA101 for $6 \mathrm{~h}$. Cells treated with DMSO were prepared as controls. Treated cells were analyzed by flow cytometry after dual AV/PI staining. (C) Raji cells were incubated in presence of $20 \mu \mathrm{M}$ Lat B, $20 \mathrm{mM}$ Tiron, $100 \mu \mathrm{M}$ DPI or $160 \mu \mathrm{M}$ ML141 for $2 \mathrm{~h}$ and then treated with $10 \mu \mathrm{g} / \mathrm{mL}$ of GA101 and the ROS marker carboxy-H2DCFDA (25mM) for $30 \mathrm{~min}, 1 \mathrm{~h}, 3 \mathrm{~h}, 6 \mathrm{~h}$ or left untreated. At each time point, cells were harvested to measure ROS production by flow cytometry. 
Supplementary Table 1: Identification of the proteins recognized by the anti-cathepsin B

antibody EML-SA361. A protein lysate of SUDHL-4 cells treated with $10 \mu \mathrm{g} / \mathrm{ml}$ of GA101

was prepared and the EML-SA361 antibody was used to carry out immunoprecipitation.

Proteins present in the immunoprecipitate were then analyzed by high-resolution mass

spectrometry using a LTQ Velos mass spectrometer.

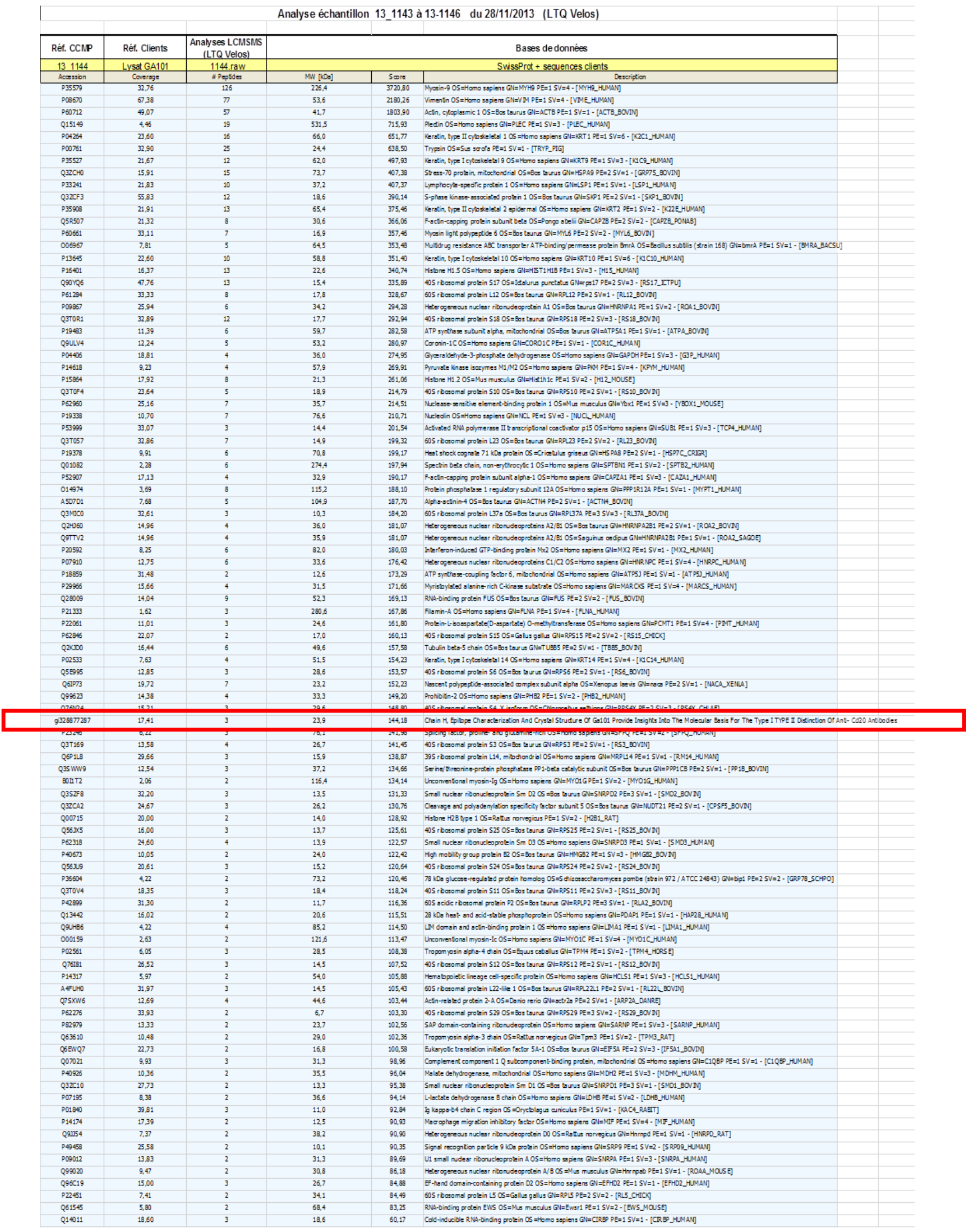




\section{Supplementary references}

Pique, M., Barragan, M., Dalmau, M., Bellosillo, B., Pons, G., Gil, J., 2000. Aspirin induces apoptosis through mitochondrial cytochrome c release. FEBS letters 480, 193-196. 